\title{
Influence of Growth Defects on the Oxidation Resistance of Sputter-Deposited TiAlN Hard Coatings
}

\author{
Peter Panjan ${ }^{1, *(D)}$, Aljaž Drnovšek ${ }^{1}$ and Goran Dražić ${ }^{2}$ (D) \\ 1 Jožef Stefan Institute, Jamova 39, 1000 Ljubljana, Slovenia; aljaz.drnovsek@ijs.si \\ 2 National Institute of Chemistry, Hajdrihova 19, 1000 Ljubljana, Slovenia; goran.drazic@ki.si \\ * Correspondence: peter.panjan@ijs.si; Tel.: +386-1-477-3278
}

Citation: Panjan, P.; Drnovšek, A.; Dražić, G. Influence of Growth Defects on the Oxidation Resistance of Sputter-Deposited TiAlN Hard Coatings. Coatings 2021, 11, 123. https://doi.org/10.3390/coatings 11020123

Academic Editor: James

E. Krzanowski

Received: 30 November 2020

Accepted: 18 January 2021

Published: 22 January 2021

Publisher's Note: MDPI stays neutral with regard to jurisdictional claims in published maps and institutional affiliations.

Copyright: (C) 2021 by the authors. Licensee MDPI, Basel, Switzerland. This article is an open access article distributed under the terms and conditions of the Creative Commons Attribution (CC BY) license (https:// creativecommons.org/licenses/by/ $4.0 /)$

\begin{abstract}
This paper reports the results of an investigation of the oxidation of a sputter-deposited TiAlN hard coating in air at temperatures of 800 and $850{ }^{\circ} \mathrm{C}$ for times ranging from $15 \mathrm{~min}$ to $2 \mathrm{~h}$. The study is focused on the role of growth defects in the oxidation process. The mechanism of oxidation at the site of the defect was studied on cross-sections made by the consecutive sectioning of oxidized coatings with the FIB technique. We found that in the early stage of oxidation, the locally intense oxidation always starts at such defects. Although the growth defects reduce the oxidation resistance of the coating locally, we believe that they do not have a decisive influence on the global oxidation resistance of the coating. There are several reasons for this. The first is that the surface area covered by growth defects is relatively low (less than $1 \%$ ). Secondly, the coating is permeable only at those defects that extend through the entire coating thickness. Thirdly, the permeability at the rim of some defects strongly depends on the density of pores at the rim of defects and how open they are. The size and density of such pores depend on the shape and size of topographical irregularities on the substrate surface (e.g., seeds, pits), which are responsible for the formation of growth defects. We also found that oxidation of the TiAlN coating is accelerated by oxygen and titanium diffusion through the pores formed by crystal grain growth in the outer alumina overlayer. Such pores are formed due to the compressive stresses in the Ti-rich oxide layer, which are caused by the large difference in molar volumes between the oxide and nitride phases.
\end{abstract}

Keywords: TiAlN hard coating; magnetron sputtering; oxidation; growth defect; focused ion beam (FIB); scanning electron microscopy (SEM); scanning transmission electron microscopy (STEM)

\section{Introduction}

The increasing application of high-speed, dry cutting technologies and the machining of difficult-to-cut workpiece materials (hard or "sticky") demands that cutting tools be protected with high-performance PVD hard coatings. Due to the high friction between the tool surface and workpiece material during machining, the temperature at the tool's cutting edge may reach more than $800{ }^{\circ} \mathrm{C}$. Therefore, the protective coating must maintain a high wear resistance (high hardness), thermal stability, and oxidation resistance at the elevated temperatures. The development of hard coatings that meet such severe requirements with subsequent improvement in the cost-effectiveness of the machining process is still a big challenge. The most common approach to meet all these requirements is the use of different multicomponent alloying hard coatings or hard coatings with a nanostructure architecture.

The first coating that largely met these requirements was TiAlN. Many conventional hard protective coatings on the market today are still based on it. The superior performance of TiAlN-coated tools in the machining of difficult-to-cut workpiece materials (e.g., stainless steels, tool steels, Ni- and Ti-alloys) is attributed to its high hot hardness [1], high oxidation resistance, and age-hardening effect [2]. TiAlN is a supersaturated pseudo-binary alloy, where $\mathrm{Al}$ atoms randomly substitute $\mathrm{Ti}$ atoms on the metal sublattice of the fcc-TiN lattice. Such substitution significantly improves the mechanical properties due to the solid solution 
hardening effect. However, this is not the only hardening mechanism present in TiAlN. It was recently found that under high thermal loading, such as during the cutting operation, the TiAlN coating decomposes by spinodal decomposition to nano-sized domains of cubic TiN and cubic AlN [3,4]. Such kinds of precipitate limits dislocation movement and generates an internal stress. Both processes, which start at a temperature around $700{ }^{\circ} \mathrm{C}$ and finish at around $900{ }^{\circ} \mathrm{C}$, increase the hardness of the coating and enhance its wear resistance. However, the disadvantage of these post-treatments is the reduction of plastic properties and embrittlement of the interface between the coating and the substrate.

As mentioned above, the resistance of hard coating materials to high-temperature oxidation is one of the most important properties. The oxidation behavior of TiAlN coatings has previously been intensively examined and reported in the literature. McIntyre et al. [5] and Ihimura et al. [6] were the first to examine the oxidation mechanisms in TiAlN coatings exposed to air at high temperature $\left(700-900^{\circ} \mathrm{C}\right)$. They found that the remarkable oxidation resistance of TiAlN hard coatings relies on its ability to form a thermally stable oxide scale that comprises a continuous and protective Al-rich top-layer and a porous Ti-rich sub-layer below (adjacent to the nitride). They observed that the growth of the oxide over-layers initially followed a parabolic law and, after reaching a certain thickness (that depends on the oxidation temperature), the growth rate decreased. Using the inert-marker technique, they showed that the mobile species were mainly $\mathrm{Al}$ (outward) and oxygen (inward), while a limited mobility of Ti species was detected. The simultaneous diffusion of $\mathrm{Al}$ atoms toward the oxide/air interface and the diffusion of oxygen to the oxide/nitride interface, accompanied by nitrogen depletion, led to the formation of oxide scale near the surface [7]. Thus, the oxidation of the coating is controlled by diffusion of aluminum and oxygen through the alumina layer. However, such a layer can act as protection against further oxidation only if it is stable at high temperature, if the layer grows slowly with a high density and if its adhesion to the coating surface is good. The mobility of the aluminum and oxygen through the Ti-rich oxide layer is considerably higher than through the Alrich oxide layer. Joshi et al. [8] found that the inward diffusion of oxygen controlled the oxidation process at temperatures smaller than $700{ }^{\circ} \mathrm{C}$ while both the inward diffusion of $\mathrm{O}$ and outward diffusion of $\mathrm{Al}$ controlled the oxidation at temperatures higher than $800{ }^{\circ} \mathrm{C}$. At an oxidation temperature below $850^{\circ} \mathrm{C}$, the thicknesses of both oxide layers are approximately the same. This indicates that the mobility of $\mathrm{Al}$ and $\mathrm{O}$ species is similar. However, a further temperature increase up to $850{ }^{\circ} \mathrm{C}$ produces a fast growth of the rutile $\mathrm{TiO}_{2}$ crystals. The reason for accelerated oxidation is the formation of micro-cracks in the oxide scale caused by the compressive stresses appearing due to the large difference in the oxide layer molar volume in comparison with the molar volume of the nitride layer. Cracks form during the heat treatment, also due to a difference in thermal expansion between the coating and the substrate. McIntyre et al. [5] and Lemke et al. [9] reported that rutile $\mathrm{TiO}_{2}$ crystals not only appear along the crack boundaries but also at the local growth defects.

Many attempts have been made to enhance the oxidation resistance of TiAlN coatings in the last two decades [10-14]. Several ways have been proposed to increase the density of the oxide scale and to retard the diffusion through it. Thus, it was found that the oxidation resistance of the TiAlN coating strongly depends on the Ti/ $\mathrm{Al}$ atomic ratio [2,15-19]. Increasing the content of aluminum within c-TiAlN promotes the formation of an $\mathrm{Al}_{2} \mathrm{O}_{3}$ layer, while the growth rate of the porous and highly permeable $\mathrm{TiO}_{2}$ layer is reduced. However, if the content of $\mathrm{Al}$ in the $\mathrm{Ti}_{1-\mathrm{x}} \mathrm{Al}_{\mathrm{x}} \mathrm{N}$ coating exceeds the maximum solubility limit $\left(x_{\max }=0.7\right)$, the transition from the cubic structure to mixed cubic wurtzite structure takes place, while the oxidation resistance decreases [4]. A special case is that the $\mathrm{Ti}_{2} \mathrm{AlN}$ coating is composed mainly of a nanolaminated MAX phase. Wang et al. found that such coating exhibited excellent oxidation resistance and thermal stability (up to $900{ }^{\circ} \mathrm{C}$ in the air) [15].

The oxidation resistance also depends on the microstructure and the morphology of the coating. Voided grain boundaries, inter-columnar porosity, and local growth defects in the TiAlN coating offer faster diffusion channels for the metal atoms outward and 
oxygen atoms inward during the oxidation, thereby lowering the oxidation resistance of a coating. A denser microstructure of coatings tends to suppress the diffusion rates of metallic and oxygen ions along the grain boundaries. The coating density and, with it, the coating oxidation resistance can be tuned to some extent by bias voltage used during deposition [5]. In general, increasing the energy of ions leads to the densification of porous column boundaries and promotes growth of smaller grains. A high coating density can also be achieved by high-power impulse magnetron sputtering (HIPIMS) [20]. This deposition technique provides conditions for effective ion bombardment, and thus increases ad-atom mobility on the surface of the growing coatings.

Another way to increase the oxidation resistance is based on the preparation of hard coatings in the form of nanolayers $[19,21]$. The layer interfaces act as a diffusion barrier for the diffusion of all atoms that participate in the oxidation process and thus improve the oxidation resistance of the coating.

The most common approach for tailoring the oxidation properties of TiAlN coatings is the addition of small concentrations (up to $\sim 15$ at.\%) of different metallic (e.g., Cr, Y, Zr, $\mathrm{Ta}, \mathrm{Nb}$ ) or nonmetallic alloying elements (e.g., $\mathrm{Si}, \mathrm{B}$ ) [22]. Dopants such as yttrium, silicon, and boron improve the high-temperature oxidation resistance of TiAlN by plugging grain boundaries $(Y)[23]$ or by forming very dense oxides $(\mathrm{Si}, \mathrm{B})[13,24]$. It is shown that large and, therefore, relatively immobile yttrium atoms with a high affinity for oxygen segregate at grain boundaries, promoting grain refinements and blocking the diffusion pathways for oxygen and substrate elements along columns and grain boundaries $[25,26]$. If TiAlN is doped with silicon or boron, then an amorphous $\mathrm{Si}_{3} \mathrm{~N}_{4}$ or $\mathrm{BN}$ phase is formed surrounding nanocrystalline TiAlN grains, forming nanocomposites and thus stimulating the further refinement of grains $[24,27,28]$. More grain boundaries prolong the diffusion paths of oxygen and thus improve the oxidation resistance of the coating. From the oxidation resistance point of view, doping the TiAlN coating with $\mathrm{Cr}$ is the most beneficial [23,29-31]. A better oxidation resistance was ascribed to: (a) the formation of mixed $(\mathrm{AlCr})_{2} \mathrm{O}_{3}$ oxide, which crystallizes faster than $\mathrm{Al}_{2} \mathrm{O}_{3}$, and (b) the possibility of $\mathrm{Cr}$ retarding the transformation of $\mathrm{TiO}_{2}$ from the anatase to rutile phase that occurs within the oxide scale at high temperature $\left(>850^{\circ} \mathrm{C}\right)$. Due to the reduction in molar volume, the phase transformation is accompanied by the formation of pores and cracks. Therefore, the oxidation rate increases. The phase transformation of anatase to rutile $\mathrm{TiO}_{2}$ can also be delayed by $\mathrm{Zr}$ [32-34] or avoided by Ta alloying [14,35-37].

There are only few papers in the literature dealing with the role of growth defects during the oxidation process of hard coatings $[5,38,39]$. The influence of defects on the oxidation resistance of sputter-deposited TiAlN is briefly mentioned in an article by McIntyre et al. [5]. Their role in the oxidation process is discussed in more detail in the paper published by Lembe et al. [9]. They studied the influence of the growth defects on the localized oxidation behavior of TiAlN/CrN superlattice coatings deposited by arc bond sputtering (ABS) technology. The defect structure that surrounds a droplet leaves a gap between the growth defect and the coating. They observed localized oxidation at sites of such defects. Fernades et al. [39] also demonstrated that the oxidation of TiSiVN coatings is controlled by the formation of a silicon oxide diffusion barrier, which is affected by nodular defects in the as-deposited film. Recently, our research group published the results of the investigation of the high-temperature oxidation of nanolayered CrVN-based coatings $[40,41]$. We found that the first oxidation products appear around the nodular defects in the form of $\mathrm{V}_{2} \mathrm{O}_{5}$ patches.

In our recently published study [42], we discussed the influence of growth defects on the corrosion resistance of TiAlN coatings. We found that pitting corrosion occurring at growth defect sites has a very deleterious effect. In these sites, the corrosive medium dissolves the substrate material, which results in the collapse of the coating. The goal of present study is to examine in more detail if the growth defects also have an important influence during the high-temperature oxidation. Based on the experimental results, the oxidation mechanisms in the early stage of oxidation are discussed. A more detailed 
explanation of the growth defect phenomenon in PVD coatings can be found in our recently published review article [43].

\section{Materials and Methods}

The industrial magnetron sputtering system (modified CC800/7, CemeCon, Germany) was used for the deposition of the TiAlN hard coating. The coating composition was Ti 23 at. $\%, \mathrm{Al} 27$ at. $\%$, and 50 at. $\%$ of N. The thickness of the coatings was around $4.1 \mu \mathrm{m}$, using a 2-fold planetary rotation. The samples analyzed in this study consisted of test plates made of cold work tool steel AISI D2 ( 58 HRC) produced by Ravne steel factory (Slovenia). The D2 plates were first ground and polished up to the roughness of about $10 \mathrm{~nm}\left(\mathrm{R}_{\mathrm{a}}\right)$. Before deposition, they were cleaned in detergents (alkaline cleaning agents, $\mathrm{pH} \sim 11)$ and ultrasound, rinsed in deionized water, and dried in hot air. In the vacuum chamber, they were first heated to about $450^{\circ} \mathrm{C}$, then in-situ cleaned by radio frequency (RF) ion etching in argon atmosphere. The RF power and the etching time were $2000 \mathrm{~W}$ and $90 \mathrm{~min}$, respectively. A standard TiAlN coating was deposited by DC-sputtering of four mosaic Ti-Al targets at $8 \mathrm{~kW}$ each. The total operating pressure was maintained at $0.75 \mathrm{~Pa}$, with the flow rates of nitrogen, argon, and krypton being 100,160 , and $110 \mathrm{~mL} / \mathrm{min}$, respectively. A DC bias of $-100 \mathrm{~V}$ was applied to the substrates. The deposition time was $135 \mathrm{~min}$. After this time, the deposition process was interrupted for an intermediate ion etching (for $60 \mathrm{~min}$ at the same conditions as during substrate cleaning). This was followed by an additional deposition of a TiAlN coating (deposition time was $30 \mathrm{~min}$ ). The intermediate etching creates new nucleation sites for the subsequently deposited nitride coating resulting in a fine-grained and less porous microstructure of the top layer [44,45].

Coated substrates were isothermally oxidized in an ambient atmosphere at temperatures of $800{ }^{\circ} \mathrm{C}$ and $850^{\circ} \mathrm{C}$ for times ranging from $15 \mathrm{~min}$ to $2 \mathrm{~h}$ using a conventional tube furnace. Under such conditions, we were able to observe the early stage of the oxidation at the sites of the growth defect. The crystal structure of both as-deposited and oxidized coatings was examined by $\mathrm{X}$-ray diffraction (XRD) with $\mathrm{CuK} \alpha$ radiation using a Bruker diffractometer (AXS Endeavor D4) in Bragg/Brentano mode and equipped with a $\mathrm{CuK} \alpha$ $X$-ray source $(0.15406 \mathrm{~nm})$. The microstructure and the coating morphology, before and after oxidation, were investigated by cross-sectional and plan-view scanning electron microscopy (SEM) using the Helios Nanolab 650i field emission scanning electron microscope. Cross-sections for detailed SEM investigation were prepared by the focused ion beam technique using the FIB source integrated into the SEM microscope. On this cross-section, SEM imaging using electrons and ions was performed. EDS element mapping was realized to determine the qualitative distribution of the elements on the FIB cross-section. EDS mapping was carried out by using the Oxford Instruments system attached to the SEM.

Scanning transmission electron microscopy (TEM) and energy-dispersive $X$-ray spectroscopy (EDS) analysis were performed, using a JEOL ARM 200 CF operated at $200 \mathrm{kV}$. All TEM images and analyses were obtained on cross-sections. The specimen for TEM characterization was prepared with a FEI Helios NanoLab 600i focus ion beam system using the standard lift-out technique.

\section{Results}

In order to understand the oxidation behavior, SEM, STEM, and EDS analyses were performed on the TiAlN hard coating before and after the oxidation test with the main emphasis focused on the role of the growth defects on the oxidation process.

\subsection{Morphology and Microstructure of As-Deposited TiAlN Hard Coating}

From the oxidation point of view, the morphology of a coating is important because the oxidation rate of a dense and fine-grained morphology is much smaller than that of the coating with a distinct columnar morphology [38]. The morphology of PVD coatings strongly depends on the deposition method and deposition parameters. Figure 1 shows the SEM plan-view image of the TiAIN hard coating sputter-deposited on a D2 tool steel 
substrate. The images were taken at low (Figure 1a,c) and high magnifications (Figure 1b,d). At a low magnification, a smooth coating surface interrupted by morphological defects (nodular defects, pinholes, craters) of various shapes and sizes can be observed. The growth defects are unevenly distributed. Sites of protruding carbides that were formed during ion etching of the substrate can also be observed. The growth defects are an unwanted phenomenon that significantly alters the morphology of PVD hard coatings [43]. Their origin is related to all topographical irregularities on the substrate surface formed during its pretreatment and ion etching, as well as by foreign particles introduced during the coating process. All these topographical irregularities on the substrate surface are transferred through the coating and even magnified due to the geometrical shadowing effect characteristic for the PVD deposition techniques [46]. Therefore, even relatively small imperfections of several tens of nanometers can grow into large micrometer-sized imperfections (growth defects) on the coating surface [43].
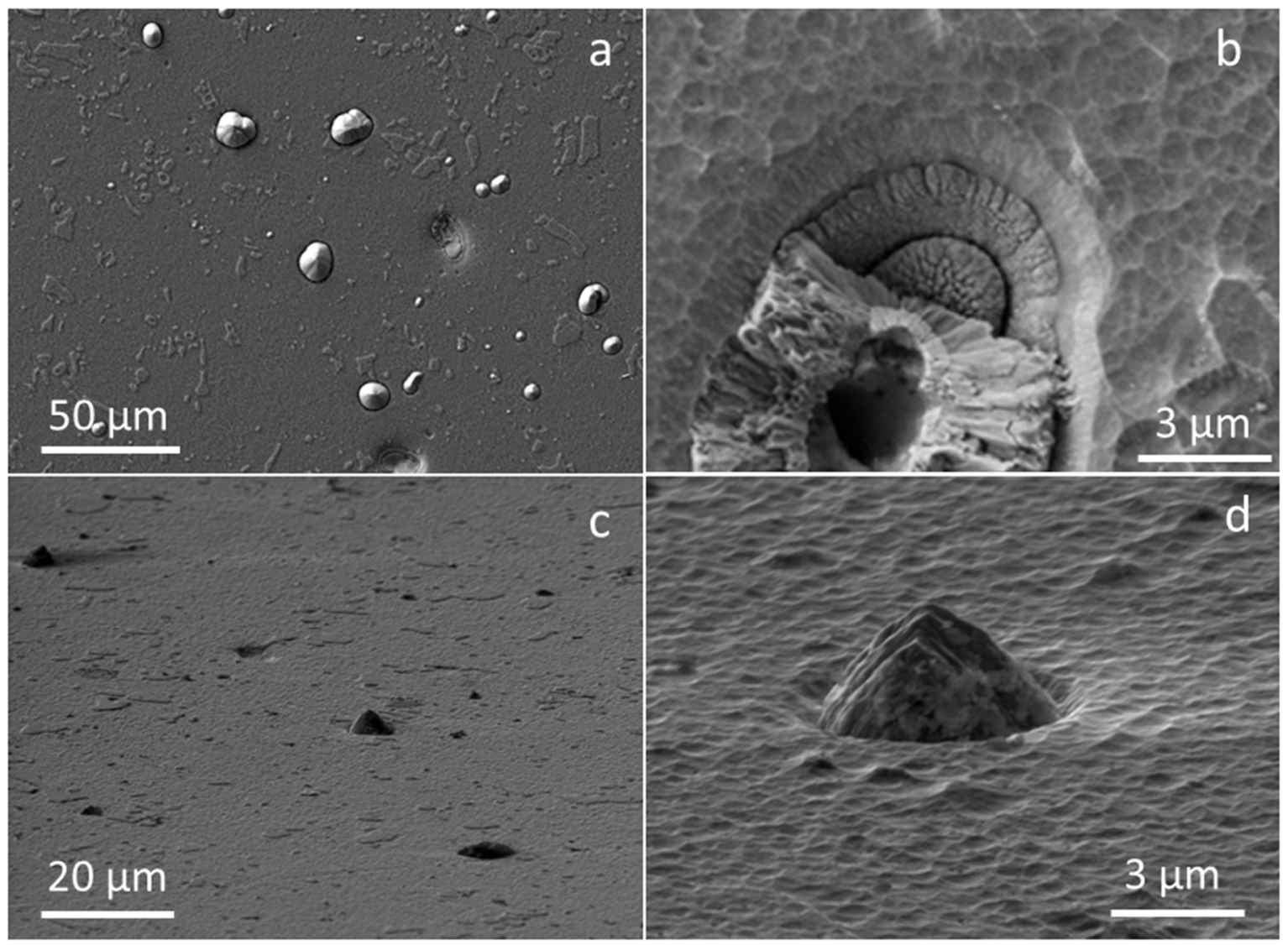

Figure 1. Plan-view SEM images of as-deposited TiAlN hard coating deposited onto D2 tool steel substrate. SEM images were recorded at low $(\mathbf{a}, \mathbf{c})$ and high $(\mathbf{b}, \mathbf{d})$ magnifications, while the images on the bottom $(\mathbf{c}, \mathbf{d})$ were taken by tilting the sample by approximately $20^{\circ}$.

At high magnification of the area between various protrusions, we can see that it exhibited a faceted domain-like morphology. The mean size of the domains is about $1 \mu \mathrm{m}$. Such topography is characteristic for coatings prepared using an intermediate etching. Interestingly, after such treatment, the roughness of the coating surface decreases. Namely, the sides of a nodular defect and other coating protrusions etch faster than the top as the etching rate at normal incidence is much smaller than at high incidence angles $\left(\sim 50^{\circ}\right)$. This phenomenon leads to the shrinking of the nodular defects and even elimination of some smaller ones. Consequently, the surface topography also changes from the cap-shaped column tops to a dimpled surface after etching (Figure 1b,d). 
Figure 2a presents the fracture cross-sectional SEM image of a TiAlN coating deposited on a D2 tool steel substrate. The image shows that the main part of the coating exhibits a pronounced coarse columnar structure, while the upper one is compact, fine-grained, and less porous. Such a microstructure of the top layer is the result of an intermediate ion etching of the coating after about three-quarters of the deposition time, which causes an interruption of the growing columns, re-sputtering of otherwise rounded column tops, and nucleation of new grains $[44,45]$. The coating surface looks rather smooth.
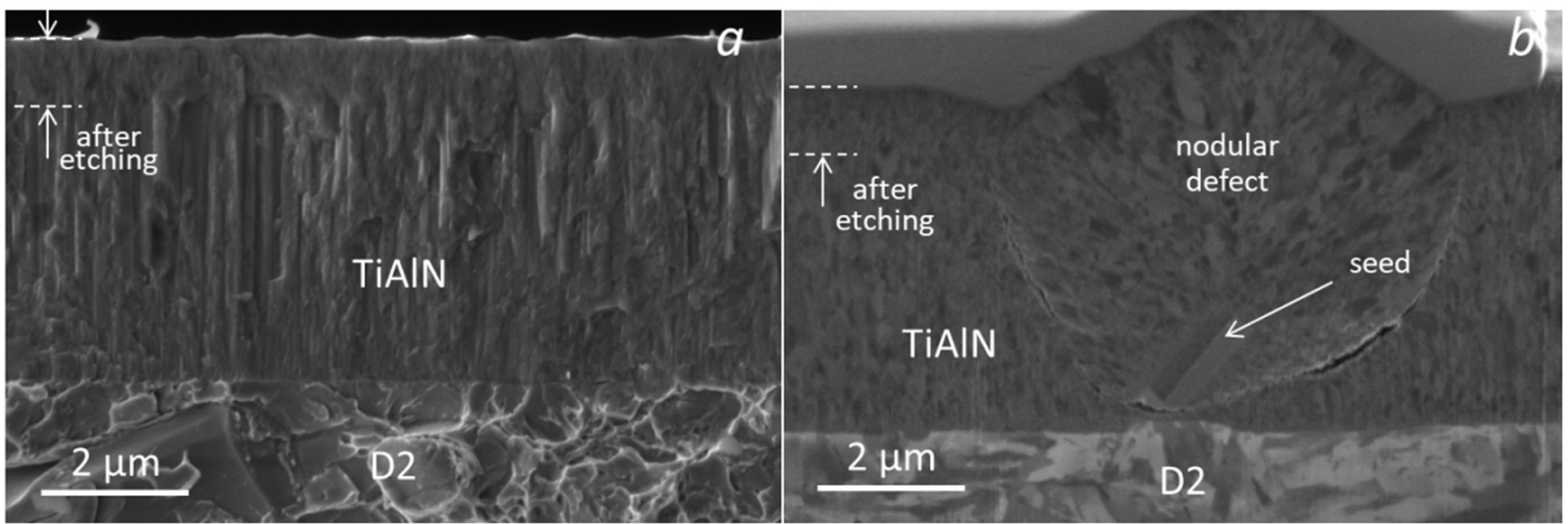

Figure 2. Fracture cross-sectional SEM image (a) and SEM image of FIB cross-section (b) of as-deposited TiAlN coating.

In the SEM image of the FIB cross-section taken using the ion beam (Figure $2 b$ ), the columnar structure of the coating cannot be noticed, while the crystal grains with different orientations are clearly visible. From a comparison of the fracture cross-sectional SEM image (Figure 2a) and SEM image of the FIB cross-section (Figure 2b), we can conclude that the individual column is not composed of a single grain but of several grains that are elongated in the growth direction. It can also be observed that the upper layer, which has grown after intermediate etching, has a more fine-grained microstructure. Beneath and around seed particles, a zone of lower density and large voids are formed due to the shadowing effect.

An even more detailed image of the microstructure and phase composition can be provided from the cross-sectional STEM image. The cross-sectional STEM bright-field micrographs of the as-deposited TiAlN coating reveal a columnar microstructure (Figure 3a,d). The diameter of the columns varies from 0.2 up to $0.4 \mu \mathrm{m}$. The columns stand tightly together but some voids are still visible in between (indicated by arrows in Figure 3a,d). STEM images clearly show that the individual columns are composed of several grains elongated in the growth direction. The grain diameter is less than $100 \mathrm{~nm}$. Their growth is repeatedly interrupted by a re-nucleation process. Near the substrate, the microstructure consists of randomly oriented small grains. Some form V-shaped columns due to the crystal grains with a certain orientation, which grow faster and gradually overgrow the slower-growing ones. At the flat substrate surface, the crystal grains are elongated in the growth direction, while they have a feather-like appearance in the area above the seed particle (Figure 3d) or other protrusions (e.g., at site of carbide, Figure 3a). It is evident that at such substrate surface irregularities, the columns do not grow normal to the surface but grow toward the adatom source with a change in column shape. 


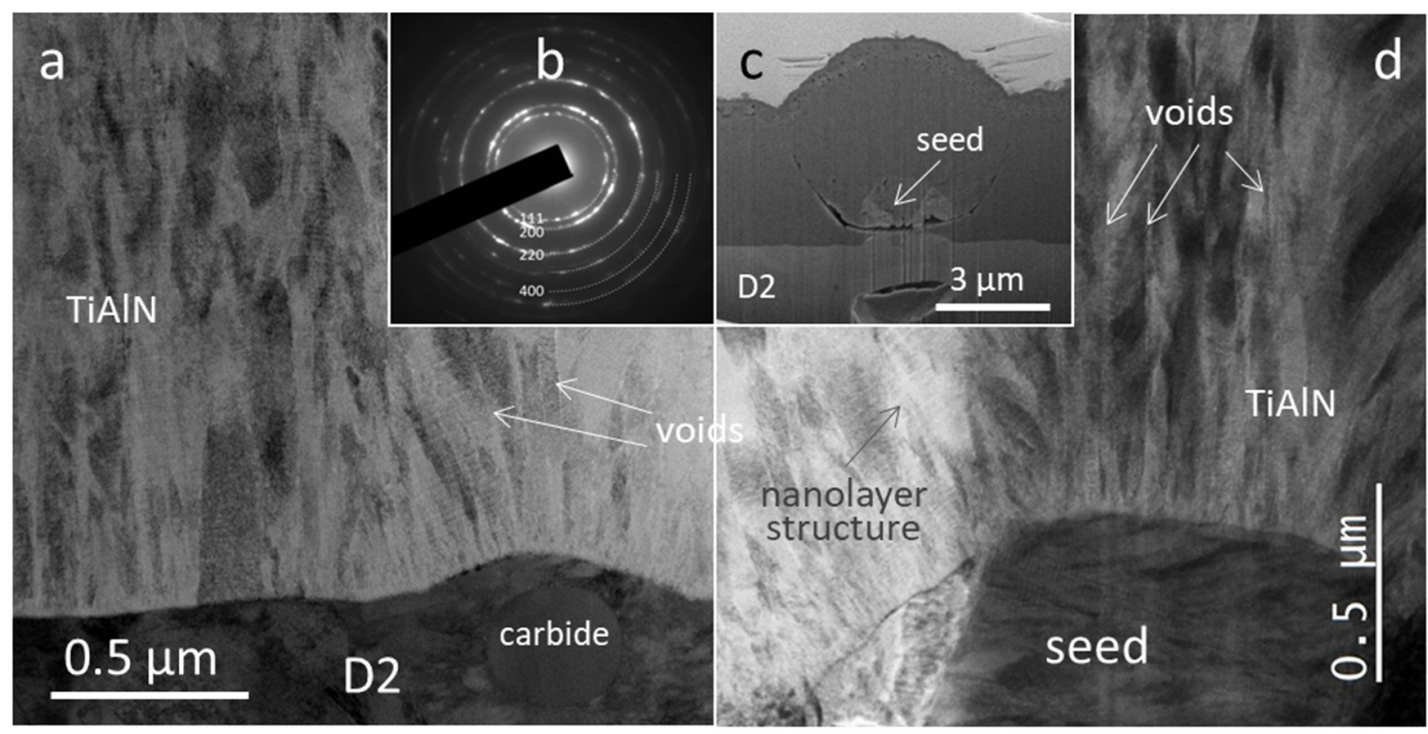

Figure 3. STEM image showing columnar morphology and nanolayer structure of sputter-deposited TiAlN coating outside (a) and inside the nodule defect (d). The corresponding electron diffraction patterns and SEM image of the FIB cross-section of the nodular defect are shown in insets $(\mathbf{b})$ and (c), respectively. A step-like feature on the substrate surface under the seed particle (inset c) indicates that the seed existed on the substrate surface already before ion etching.

The STEM image of the as-deposited TiAlN coating also reveals that it has a nanolayered structure. The coating is composed of alternating Al-rich (bright) and Ti-rich (dark) layers with a modulation period of about $35 \mathrm{~nm}$. Such a nanolayer structure is caused by the rotation of the sample that periodically approaches toward and moves away from the mosaic target. Both the angle-of-incidence of the depositing atom flux and deposition rates change constantly during the deposition process. A typical diffraction pattern recorded from a larger area of the TiAlN film is shown as inset $b$ of Figure 3. The diffraction rings are continuous due to the small grain size and their different orientations. All of them can be attributed to the face-centered-cubic TiN-related structure. X-ray diffraction analyses also showed that the as-deposited coating has the fcc crystal structure and a (200) preferential orientation (Figure 4).

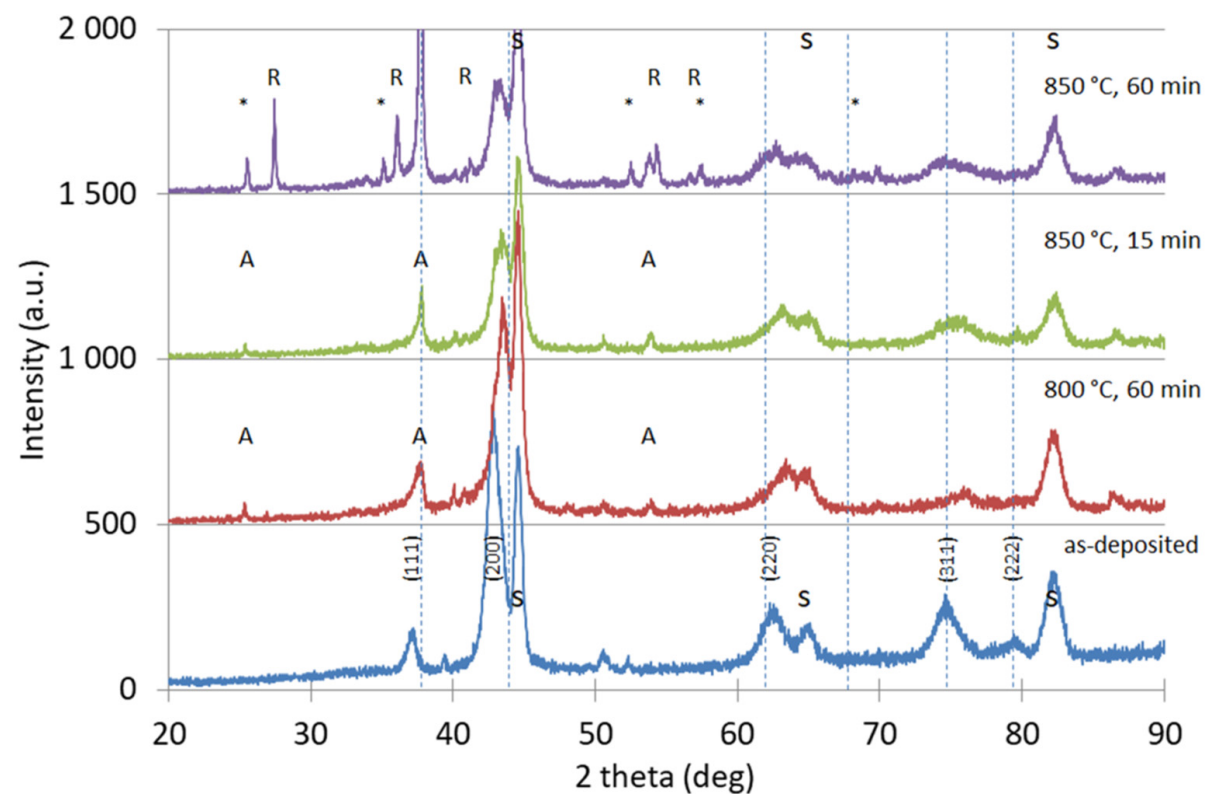

Figure 4. X-ray diffraction patterns of as-deposited and oxidized TiAlN hard coatings. The oxidation was performed for different temperatures and times (designation of peaks: s—substrate, A—anatase, $\mathrm{R}$-rutile, ${ }^{*}$ - $\alpha$-aluminum oxide). 


\subsection{Coating Morphology and Microstructure after Oxidation at $800{ }^{\circ} \mathrm{C}$}

The first sample was oxidized at $800^{\circ} \mathrm{C}$ for $60 \mathrm{~min}$. The high-magnification SEM image shows that the whole surface is covered by very fine blade-like oxide crystals (Figure $5 b, d$ and Figure 6a). EDS maps on the FIB cross-sections of the oxidized sample (Figures 6 and 7) show that the outermost region of the oxide scale is aluminum oxide. However, there is no indication of an alumina crystal structure by X-ray diffraction (Figure 4). Thus, it can be concluded that aluminum oxide has an amorphous or very-fine-grained microstructure. The XRD analysis of the oxidized sample revealed the presence of anatase $\mathrm{TiO}_{2}$ in addition to nitride phases. As already mentioned in the introduction, the thin aluminum oxide layer that formed in the initial stage of oxidation on the top of the TiAlN coating strongly slows down the further oxidation process and thus provides an excellent protective effect in the area free of growth defects $[5,38]$. However, oxidation continues to take place intensively at the sites of certain growth defects. Around some of these defects, dark circular regions of various diameters (up to $40 \mu \mathrm{m}$ in diameter) were formed (Figure 5a, inset in Figure 6a, inset in Figure 7a). The formation of such dark circles can be related to the diffusion of titanium on the oxide overlayer. The diffusion intensity depends on how open the pathways around the growth defect toward the substrate are. Therefore, such circular regions do not appear around all growth defects. Some defects where no such regions can be observed are marked with arrows in Figure 5a. Around those defects where they do occur, however, their diameter is very different, depending on oxidation intensity.

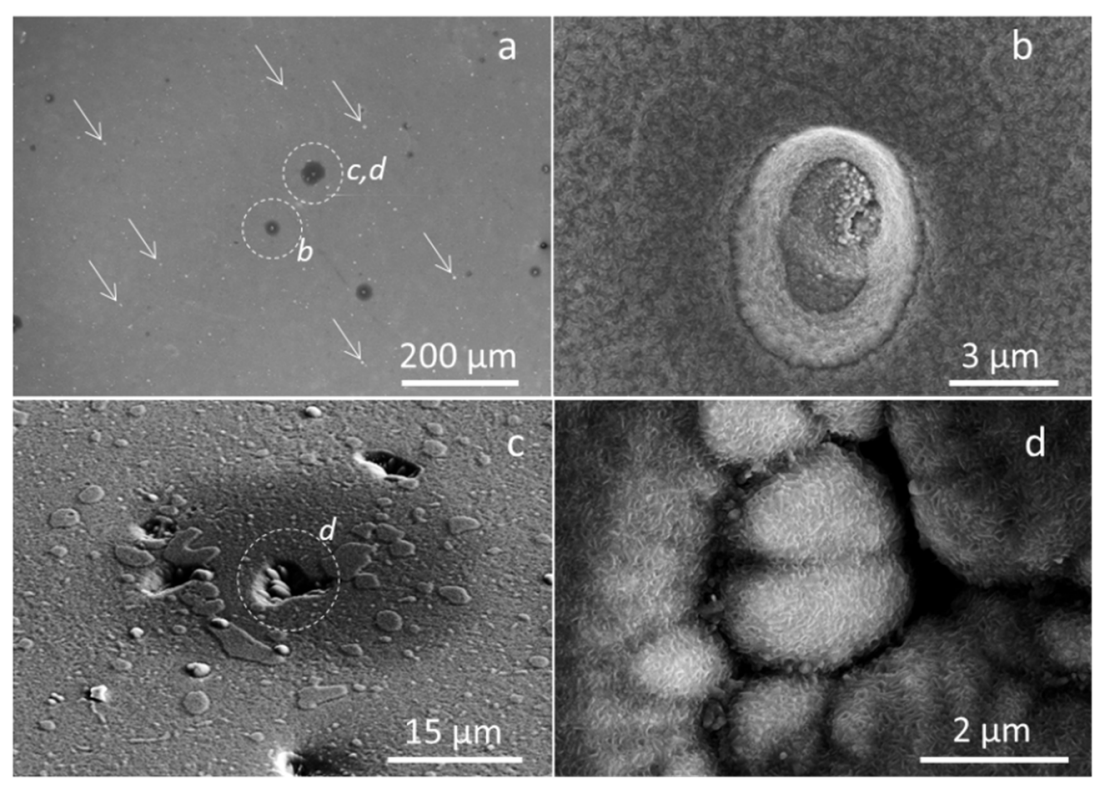

Figure 5. Plan-view SEM images of TiAlN hard coating oxidized at $800^{\circ} \mathrm{C}$ for $60 \mathrm{~min}$. SEM images were recorded at low $(\mathbf{a}, \mathbf{c})$ and high $(\mathbf{b}, \mathbf{d})$ magnification, while the image $(\mathbf{c})$ was taken by tilting the sample by approximately $20^{\circ}$. 

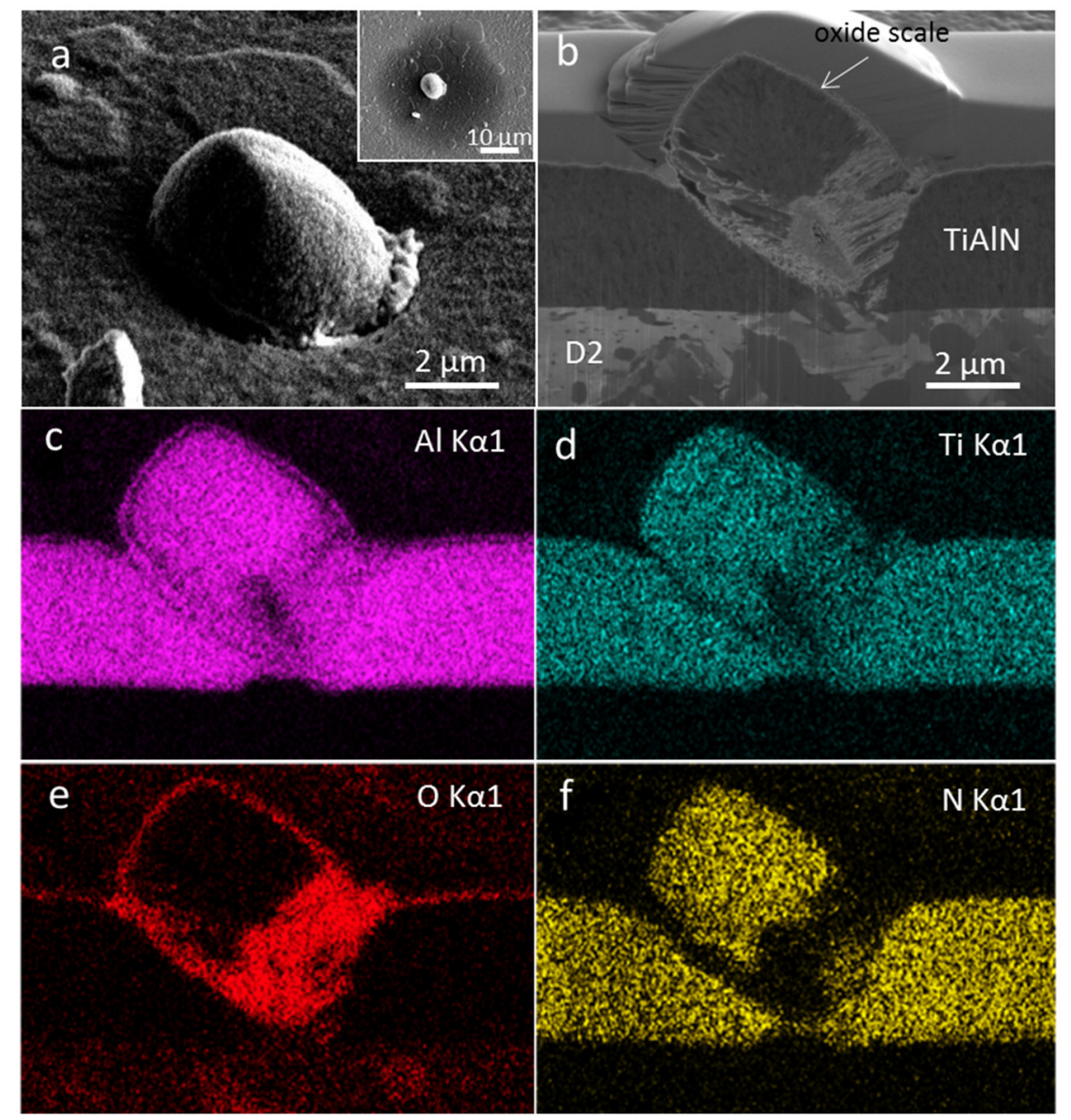

Figure 6. SEM images of nodular defect in sputter-deposited TiAlN hard coating oxidized at $800{ }^{\circ} \mathrm{C}$ for 60 min: (a) SEM images at high and low (inset) magnification, (b) SEM image of the FIB crosssection of the same defect and corresponding elemental maps (c-f).

Additional information about the oxidation process can be obtained from the SEM image of the FIB cross-section (Figures $6 \mathrm{~b}$ and $7 \mathrm{~b}$ ). In such images, a thin two-layer oxide structure (total thickness $\sim 200 \mathrm{~nm}$ ) is visible. As expected, the EDS elemental maps revealed that the top layer is Al-rich, whereas the bottom one is Ti-rich. This is consistent with the results of the investigations by other researchers $[5,38]$ who found that the layered oxide scale of TiAlN coatings is attributed to the simultaneous outward diffusion of aluminum (through the oxide/air interface) to grow the alumina layer and inward diffusion of oxygen (toward the oxide/nitride interface), to form a Ti-rich oxide layer. The continuous and homogeneous alumina layer prevents the further oxidation of the TiAlN coating. However, as mentioned before, such a continuous layer is interrupted at the sites of the growth defects. SEM images of the FIB cross-section confirm that the boundaries between the coating matrix and the defects are very porous (Figures $6 \mathrm{~b}$ and $7 \mathrm{~b}$ ). Some of the pores are extended through the entire the coating thickness. Through such pores, oxygen can reach the substrate while elements from the substrate may penetrate into the coating surface. The EDS elemental maps shown in Figures 6 and 7 confirm an intense localized oxidation at sites of selected nodular defects and pinholes, respectively. 

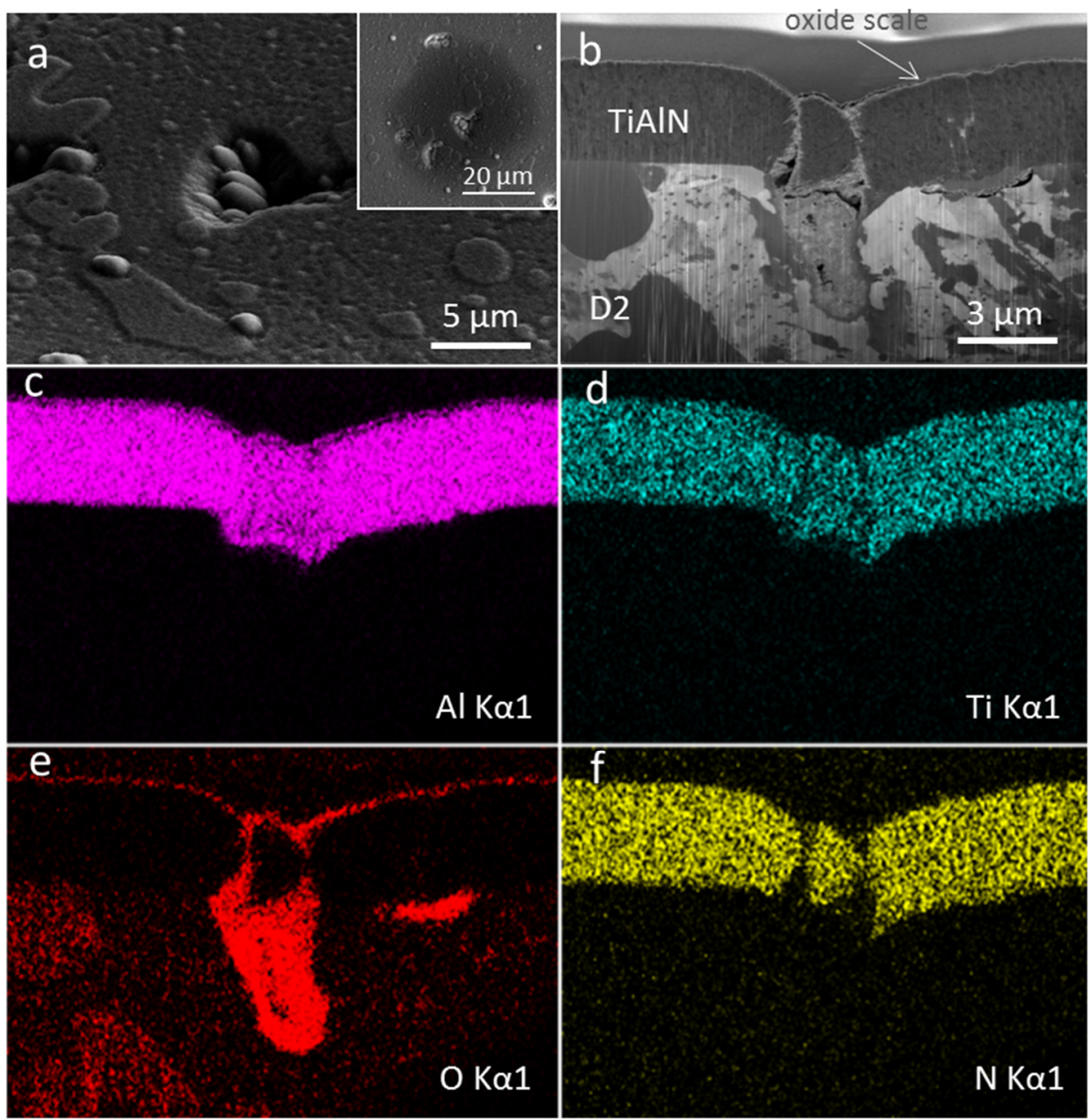

Figure 7. SEM images of pinhole in sputter-deposited TiAlN hard coating oxidized at $800{ }^{\circ} \mathrm{C}$ for 60 min: (a) SEM images at high and low (inset) magnification, (b) SEM image of FIB cross-section of the same defect, and (c-f) corresponding elemental maps [43].

\subsection{Coating Morphology and Microstructure after Oxidation at $850^{\circ} \mathrm{C}$}

The oxide double layer of almost the same thickness as in the previous case was formed on the sample that was oxidized at $850{ }^{\circ} \mathrm{C}$ for $15 \mathrm{~min}$. The X-ray spectrum of this sample is similar to the sample that was oxidized at $800^{\circ} \mathrm{C}$ (Figure 4). In addition to the expected peaks belonging to the nitride phase, peaks corresponding to the anatase $\mathrm{TiO}_{2}$ phase can be identified, but there is no indication of crystalline alumina. From this, we can conclude that the alumina top layer is still amorphous. As in the case of the sample oxidized at $800{ }^{\circ} \mathrm{C}$ for $60 \mathrm{~min}$, a dark circular region was noticed at some growth defects, but its diameter is about twice as large. However, in addition to these circles, a network of dark patches of irregular shape and different size (up to about $20 \mu \mathrm{m}$ ) was observed (Figure 8a, inset in Figure 9a). The occurrence of these patches cannot be associated with the diffusion processes along the sub-dense column boundaries, because the average distance between adjacent patches is much larger than the average inter-column distance. They also cannot be related to the growth defects, because the surface density of patches is much higher. As in the case of the dark circular region around the growth defects, the formation of these patches can be explained by the diffusion of titanium onto the surface of the oxide overlayer through the pores in the top alumina layer. How such pores can be formed will be explained later. 


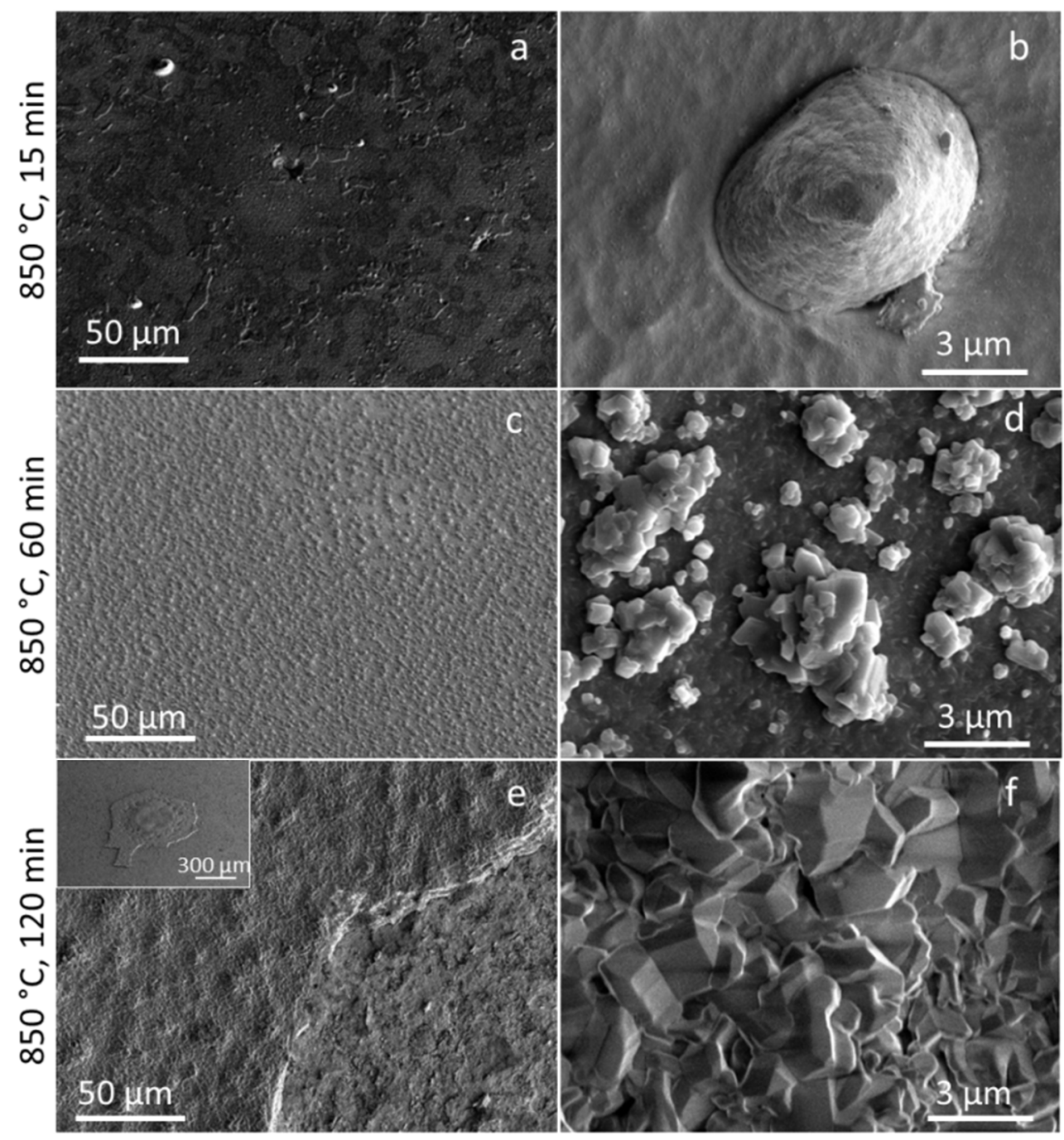

Figure 8. Plan-view SEM images of TiAlN hard coating oxidized at $850{ }^{\circ} \mathrm{C}$ for $15(\mathbf{a}, \mathbf{b}), 60(\mathbf{c}, \mathbf{d})$, and $120 \mathrm{~min}(\mathbf{e}, \mathbf{f})$. SEM images were recorded at low $(\mathbf{a}, \mathbf{c}, \mathbf{e})$ and high $(\mathbf{b}, \mathbf{d}, \mathbf{f})$ magnification.

The fracture cross-sectional SEM image of the TiAlN coating after short-term oxidation at $850{ }^{\circ} \mathrm{C}$ (Figure 10a) shows similar microstructure features as the as-deposited one, except a thin oxide scale (app. $200 \mathrm{~nm}$ thick) is present on the coating surface. The same finding applies for the SEM image of the FIB cross-section (Figure 10b).

It is evident from both types of images that the oxide overlayer is continuous and homogeneous except at sites of growth defects (Figures $9 \mathrm{~b}$ and 10b). The EDS elemental maps on the FIB cross-section of the pinhole (Figure 9) shows that it is filled with oxidation products throughout its depth. 


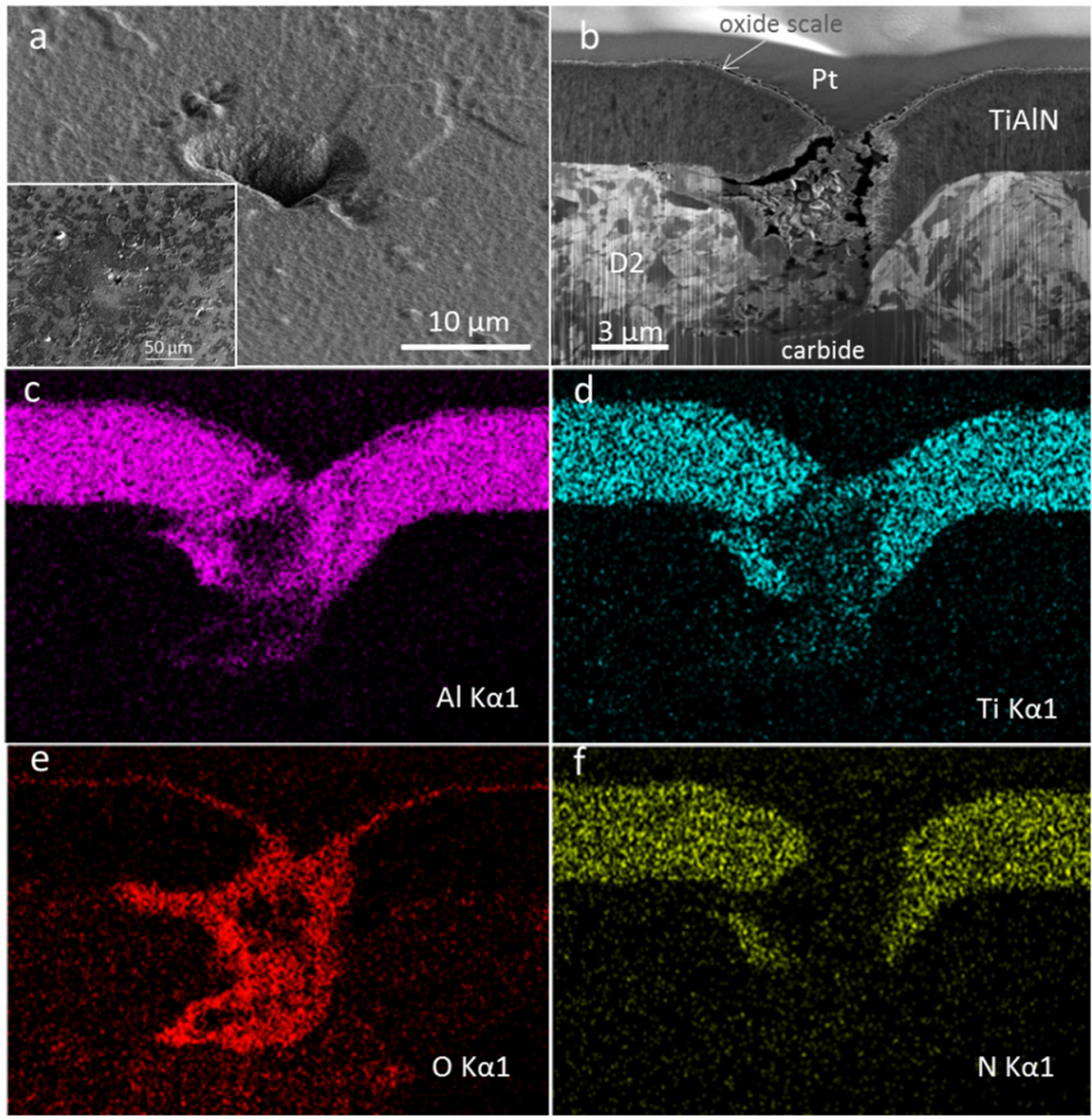

Figure 9. SEM images of pinhole in sputter-deposited TiAlN hard coating oxidized at $850{ }^{\circ} \mathrm{C}$ for 15 min: (a) SEM images at high and low (inset) magnification; (b) SEM image of the FIB cross-section of the same defect, and (c-f) corresponding elemental maps.

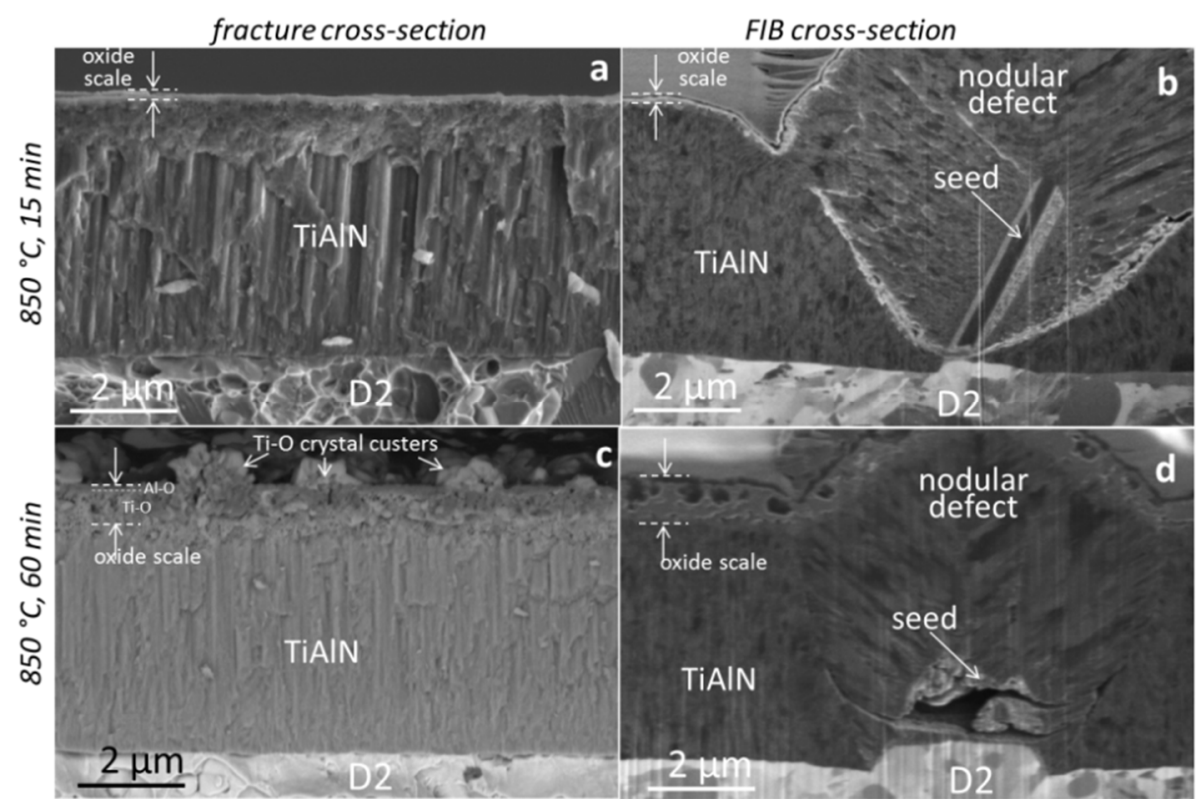

Figure 10. Fracture cross-sectional SEM images $(\mathbf{a}, \mathbf{c})$ and SEM images of FIB cross-sections $(\mathbf{b}, \mathbf{d})$ of TiAlN coating after oxidation at $850^{\circ} \mathrm{C}$ for $15(\mathbf{a}, \mathbf{b})$ and $60 \mathrm{~min}(\mathbf{c}, \mathbf{d})$. 
As the oxidation time at $850{ }^{\circ} \mathrm{C}$ increased from 15 to $60 \mathrm{~min}$, more pronounced changes occurred. Clusters of the large faceted $\mathrm{TiO}_{2}$ crystallites with a rutile structure were observed to grow on the oxide overlayer (Figures $8 \mathrm{c}, \mathrm{d}, 11 \mathrm{a}$ and $12 \mathrm{a}$ ). X-ray analysis of the sample oxidized at $850{ }^{\circ} \mathrm{C}$ for 60 min confirms the formation of the rutile $\mathrm{TiO}_{2}$ phase (Figure 4). However, the anatase phase, which is attributed to the titanium oxide layer at the interface with the nitride coating, is still present. Additionally, some peaks of the $\alpha$-aluminum oxide phase were also detected. The EDS elemental maps, carried out at the oxidized surface, shows discontinuous and evenly distributed islands rich in the $\mathrm{TiO}_{2}$ rutile phase on the top of an Al-rich oxide layer (Figure 11). It can be noticed that the size, shape, and surface density of these islands are comparable to the dark patches observed on the surface of samples oxidized at the same temperature for $15 \mathrm{~min}$. The formation of similar $\mathrm{TiO}_{2}$ crystallites in the microcracks of the alumina overlayer during oxidation of the TiAlN coating at $850{ }^{\circ} \mathrm{C}$ for $3 \mathrm{~h}$ was reported by McIntyre et al. [5]. They begin to appear after several hundred nanometers of oxide overlayer growth. The authors reported the appearance of crack networks upon oxidation of the $\mathrm{Ti}_{0.5} \mathrm{Al}_{0.5} \mathrm{~N}$ hard coatings deposited at low bias voltages and their disappearance when the bias voltage was increased to $-150 \mathrm{~V}$. This dependency on the bias voltage was associated with an increase in residual stress with increasing bias voltage. The formation of cracks upon heating was explained by different thermal expansion coefficients of the substrate and coating.
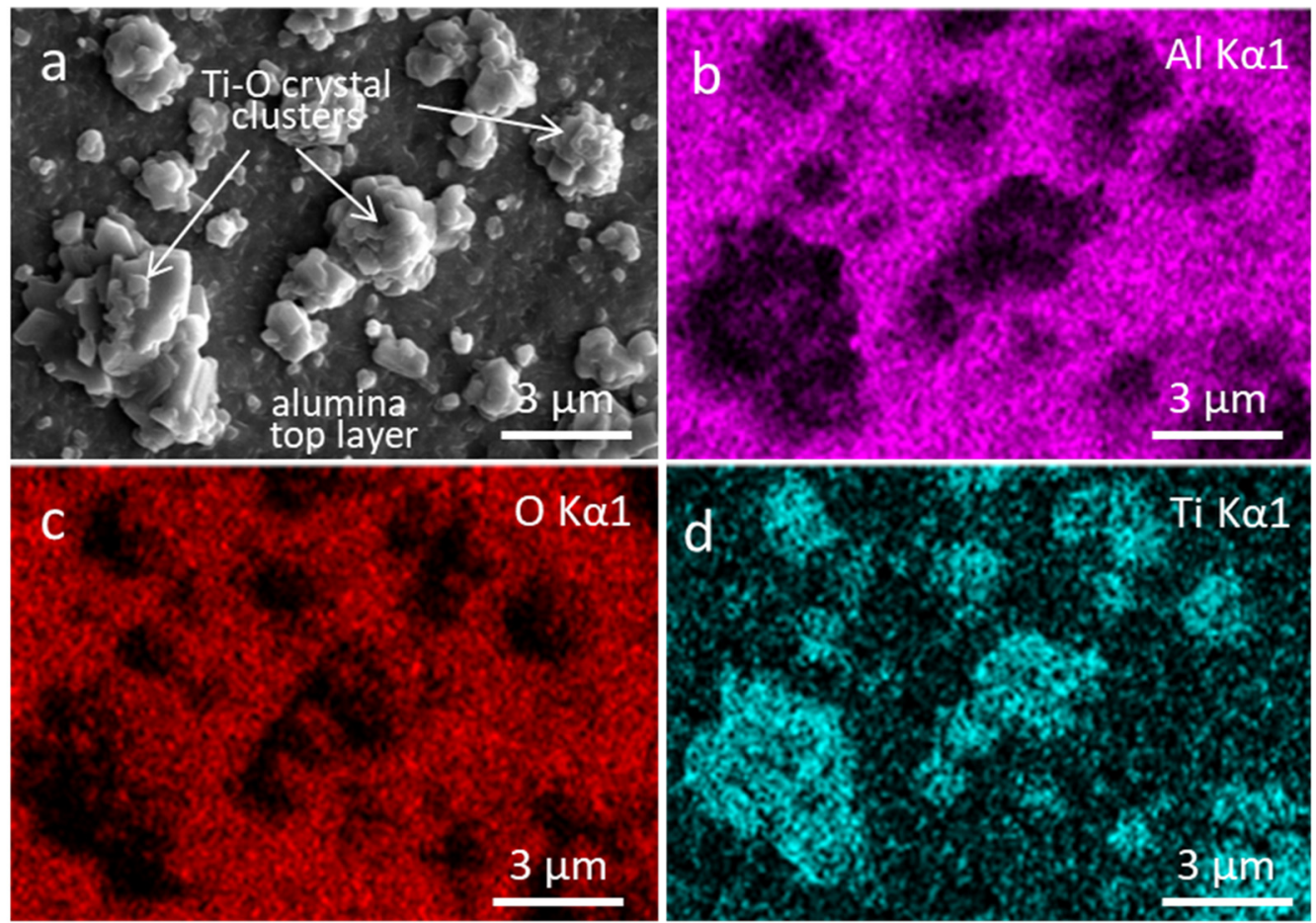

Figure 11. Top-view SEM image of the surface of the TiAlN coating oxidized at $850{ }^{\circ} \mathrm{C}$ for 60 min (a) and the corresponding elemental maps $(\mathbf{b}-\mathbf{d})$. 


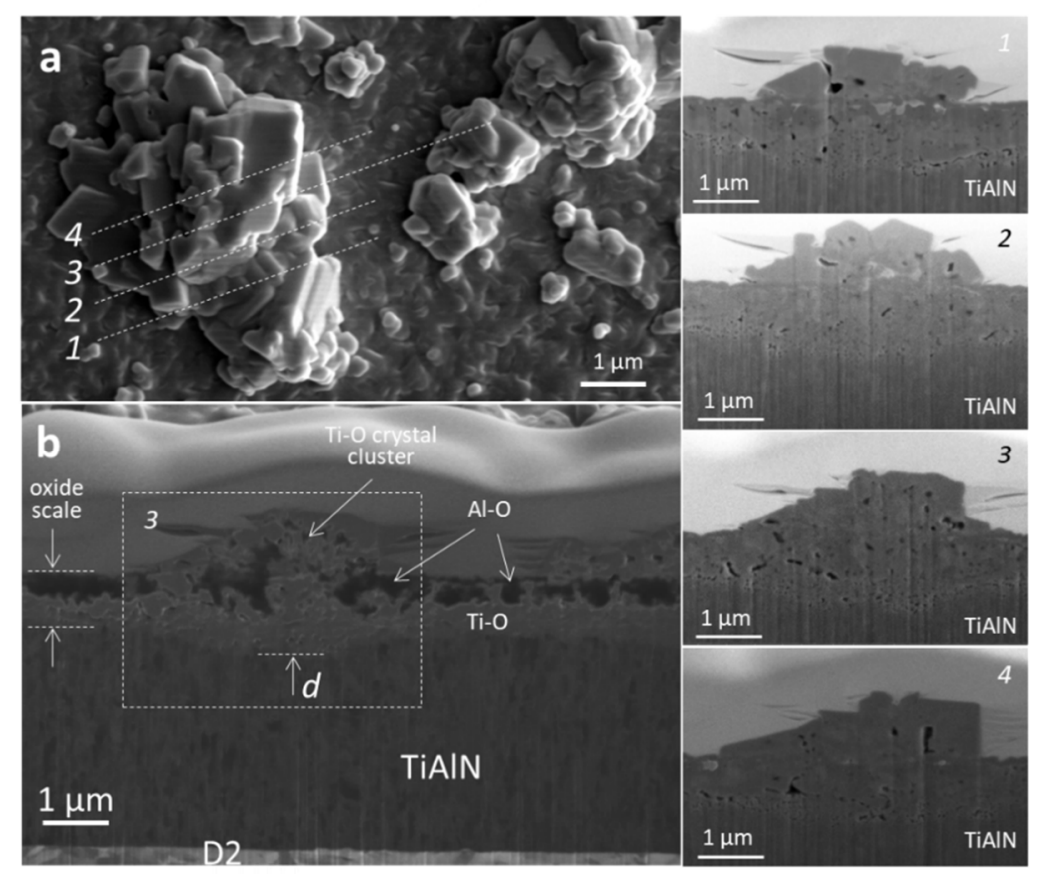

Figure 12. Top-view SEM image of the TiAlN coating surface after oxidation at $850{ }^{\circ} \mathrm{C}$ for $60 \mathrm{~min}(\mathbf{a})$; SEM images of FIB cross-sections through larger cluster of $\mathrm{TiO}_{2}$ crystals in direction marked with dashed lines 1, 2, 3, and 4; (b) ion-generated SEM image of FIB cross-section in direction marked with dashed line 3.

We found that even if the oxidation time was extended to $60 \mathrm{~min}$, no microcracks on the aluminum oxide surface were observed. In order to reveal the origin of $\mathrm{TiO}_{2}$ crystallites on top of the Al-rich oxide layer, consecutive sectionings through the center of $\mathrm{TiO}_{2}$ islands were made by the FIB technique. In Figure 12, four dashed lines marked with numbers 1 to 4 indicate the positions where the cross-sections were made. SEM images of consecutive cross-sections are shown in Figure 12 (images on the right). We were interested in whether there were any inhomogeneities, pores, or other defects in the nitride coating under the clusters of crystals. Such types of defects would allow faster diffusion of all species that participate in the oxidation process. The SEM images do not confirm that such defects are present in the nitride layer. It is obvious, however, that the oxidation front at the sites of the oxide crystallites reaches deeper into the nitride coating than outside of them (marked with " $d$ " in Figure 12b). This means that the diffusion of oxygen at these sites is faster due to the higher permeability of the upper alumina layer. The ion-generated SEM image of the FIB cross-section (Figure 12b) reveals the reason behind the higher permeability of the A-rich oxide layer at these places. In this image, the aluminum and Ti-rich oxide layers are dark and bright areas, respectively. The boundary between the upper Al-rich oxide layer and the lower Ti-rich oxide layer is very uneven. We see that the titanium oxide has spread in the form of protrusions into the Al-rich oxide layer. The typical distance between the two protrusions is less than a micrometer. In some places, the titanium oxide phase also appears on the surface where clusters of large $\mathrm{TiO}_{2}$ crystals are formed. We believe that the formation of such protrusions is related to compressive stresses in the Ti-rich layer that appeared due to the large difference in the titanium oxide molar volume in comparison with the molar volume of the nitride layer. Such stresses can separate the grain boundaries in the otherwise very-fine-grained aluminum oxide layer, and thus, open the way for the diffusion of titanium to the surface and oxygen to the oxidation front. Such a drastic change in oxidation of the TiAlN coating at $850{ }^{\circ} \mathrm{C}$ for $60 \mathrm{~min}$ could be related to the formation of crystalline aluminum oxide from the amorphous one. Such an interpretation is also supported by the findings of other authors. Namely, many years ago, some authors [6,47] reported that during high-temperature oxidation of the TiAlN coating, the oxygen can 
diffuse through the pores formed by the grain growth of the $\mathrm{Al}_{2} \mathrm{O}_{3}$ crystal in the outer alumina layer during high-temperature oxidation of TiAlN. Münz was the first who found that there is no indication of an $\mathrm{Al}_{2} \mathrm{O}_{3}$ crystal structure below $800^{\circ} \mathrm{C}$, while a drastic change in the oxidation behavior occurs above this temperature due to the formation of crystalline alumina from the amorphous one [47].

We must not forget, however, that after extending the oxidation time to $60 \mathrm{~min}$, the oxidation taking place at sites of growth defects is even more intensive. Figure 13a shows that large oxide crystallites were formed at the rim of the nodular defect. However, as already mentioned, oxidation does not take place with the same intensity around all growth defects, which depends on the density of the pores at the rim of the defects and on how open they are.

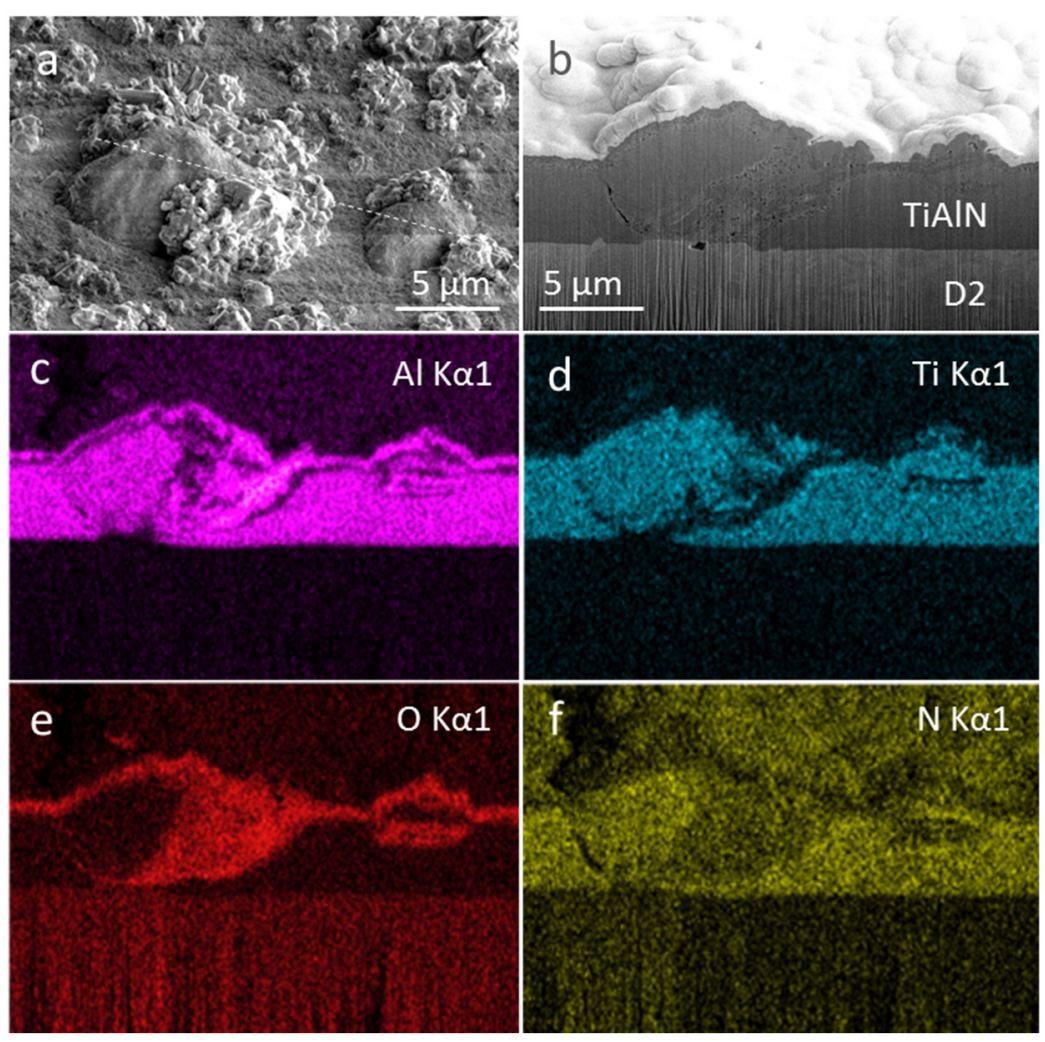

Figure 13. SEM images of nodular defect in sputter-deposited TiAlN hard coating oxidized at $850{ }^{\circ} \mathrm{C}$ for $60 \mathrm{~min}$ : (a) SEM image, (b) SEM image of FIB cross-section of the same defect, and (c-f) corresponding elemental maps.

The fracture cross-sectional SEM image of the oxidized film (Figure 10c) shows the presence of a thin two-layer oxide structure, with a porous inner Ti-rich oxide layer and an outer compact Al-rich oxide layer. The oxide bilayer thickness increases from 0.2 to $0.95 \mu \mathrm{m}$ if the oxidation time increases from 15 to $60 \mathrm{~min}$, respectively. The structure of the oxide scale can also clearly be seen in the SEM images of the FIB cross-section (Figures 10d, 12, 13b, and 14b). The EDS maps on FIB cross-sections revealed that the porous bottom layer and the denser top layer are Ti-rich and Al-rich oxides, respectively. Discrete and unevenly distributed $\mathrm{TiO}_{2}$ crystals can be observed on the top alumina layer, while the rest of the nitride coating is still uninfluenced by the oxidation. 


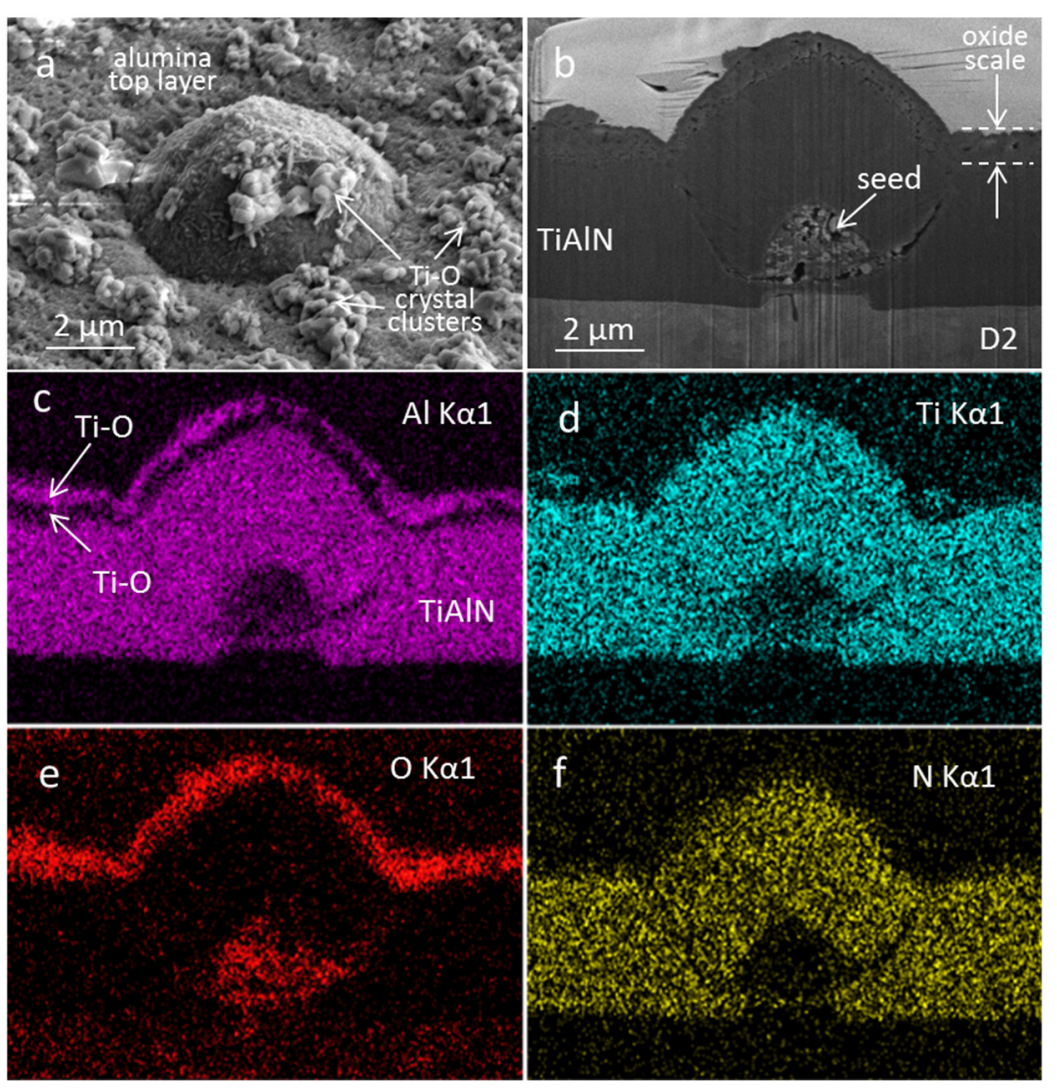

Figure 14. SEM images of nodular defect in sputter-deposited TiAlN hard coating oxidized at $850{ }^{\circ} \mathrm{C}$ for 60 min: (a) SEM image, (b) SEM image of the FIB cross-section of the same defect, and (c-f) corresponding elemental maps.

Plain-view SEM images (Figures 13a and 14a) show that a complex oxide structure was developed at sites of some growth defects. Due to the presence of under-dense regions and pores at the rim of the growth defect, a high amount of Ti ions is supplied in this zone. As a result, the localized oxidation and formation of large oxide crystals around many defects can be observed. This phenomenon is not equally pronounced around all growth defects, due to the different degree of porosity at the boundary between the coating matrix and the defect. Such porosity is influenced by the shape and size of the topographical irregularities (e.g., seeds, pits) on the substrate surface that are responsible for the formation of the growth defects $[43,46]$. If the seed has a smooth morphology, then the nodule looks like a cone, while a seed with complex morphology results in the growth of a nodular defect with irregular surface features. When an irregularly shaped seed is coated, the particle flux cannot reach the area underneath the seed, due to the shadowing of the particle flux, and thus causes formation of voids below the particles. The coating on such kinds of seeds results in a highly nonuniform coverage with a practically uncoated area underneath the seed. Figure 13 shows the top-view SEM image of the nodular defect where intensive oxidation has occurred. The SEM image of a FIB cross-section reveals open pathways at the rim of the defect. It is quite different in the case of a nodular defect in Figure 14, where almost no oxidation products at the edge of the defect are observed. From the SEM image of the FIB cross-section in Figure 14, we can see that the boundary between the nodular defect and coating matrix is much less porous than in the previous case. This is most likely due to the fact that the shape of the seed is more regular. In the case of cavities, the uniformity of coverage and, thus, formation of pores depend on the aspect ratio (depth/hole diameter), as well as from the angular distribution of the impinging vapor flux [43,46].

The microstructure of the oxide layers at the site of the nodular defect was analyzed in more detail with a STEM microscope. The FIB lift-out technique was applied for the 
preparation of the lamella from the nodular defect shown in Figure 14. Figures 15-17 show the bright-field STEM images and the STEM-EDS maps of the oxide scale at the nodular defect site and outside it. In these micrographs, a dense and fine-grained Al-rich oxide top layer can be seen, while the Ti-rich oxide underlayer has a coarser polycrystalline microstructure with a rough surface. The transformation of the amorphous alumina into the crystalline one was confirmed by both X-ray diffraction (Figure 4) as well as selectedarea electron diffraction (SAED) analysis (Figure 17b). The thickness of the oxide double layer is app. $0.95 \mu \mathrm{m}$, while about $3.8 \mu \mathrm{m}$ of the coating is not yet oxidized. Figure $15 \mathrm{~d}, \mathrm{f}$ and Figure 16d show the elemental maps of Al- and Ti-rich oxide areas within the oxide scale. It can be seen that the interface between Al-rich and Ti-rich oxide layers is not flat. The STEM-EDX maps in Figures 15 and 16 clearly show that titanium oxide crystallites penetrate deep into the alumina layer at some places. As already mentioned, the expansion of titanium oxide into the aluminum oxide layer can be caused by compressive stresses resulting due to a large molar volume difference of $\mathrm{TiO}_{2}$ and TiAlN. Thus, the top Al-rich layer becomes porous and oxygen can more rapidly access the oxidation front. Hence, its passivation protection is significantly reduced. Based on this, it can be concluded that, in addition to localized oxidation at growth defect sites, this mechanism could also be responsible for the accelerated diffusion of titanium through the alumina layer. The result of both processes is large $\mathrm{TiO}_{2}$ crystals forming on the oxidized TiAlN coating surface.
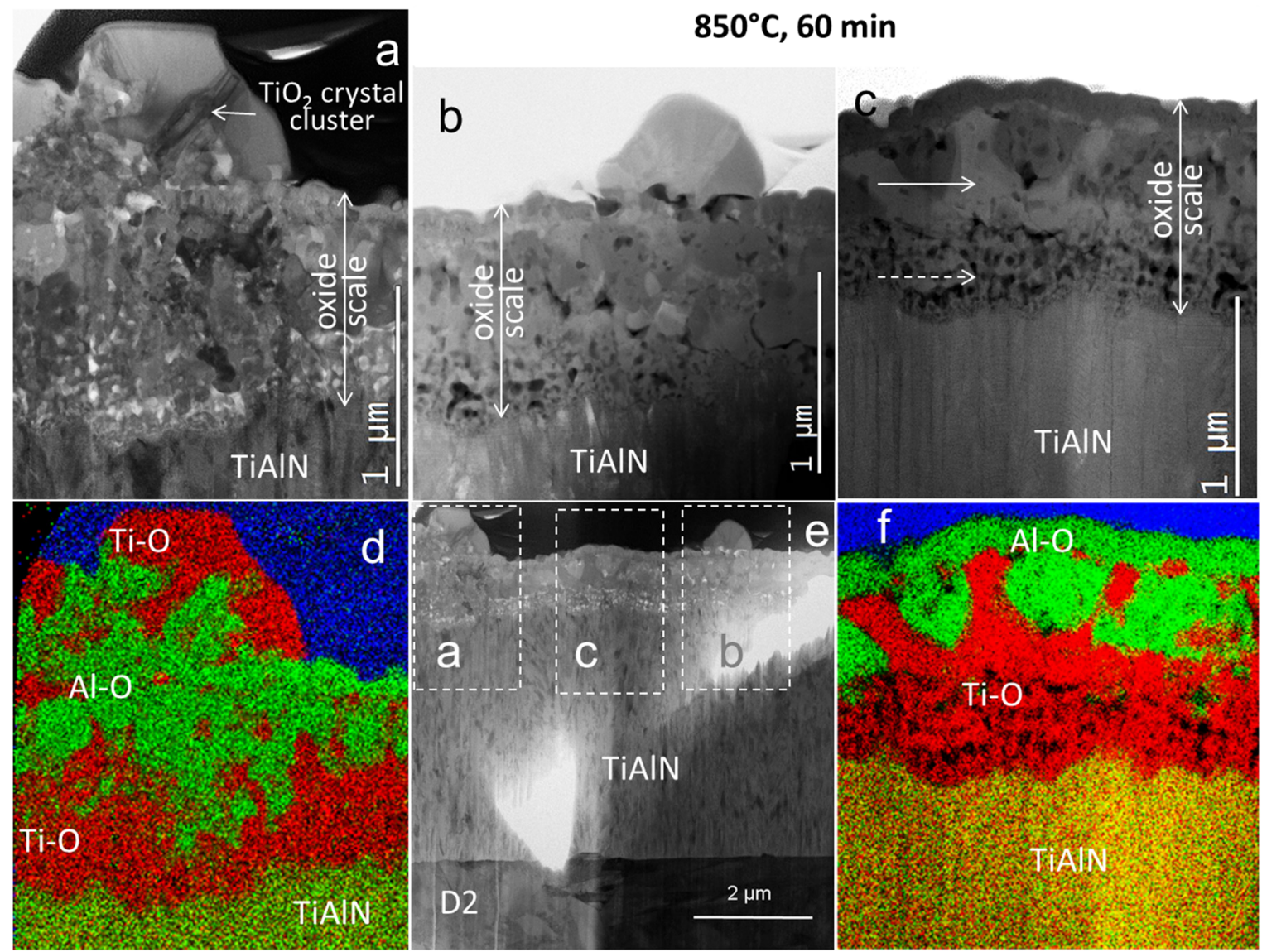

Figure 15. Bright-field STEM cross-sectional images of oxide scale $(\mathbf{a}-\mathbf{c}, \mathbf{e})$ and corresponding STEM-EDS maps (d,f) of TiAlN coating oxidized at $850^{\circ} \mathrm{C}$ for $60 \mathrm{~min}$. 


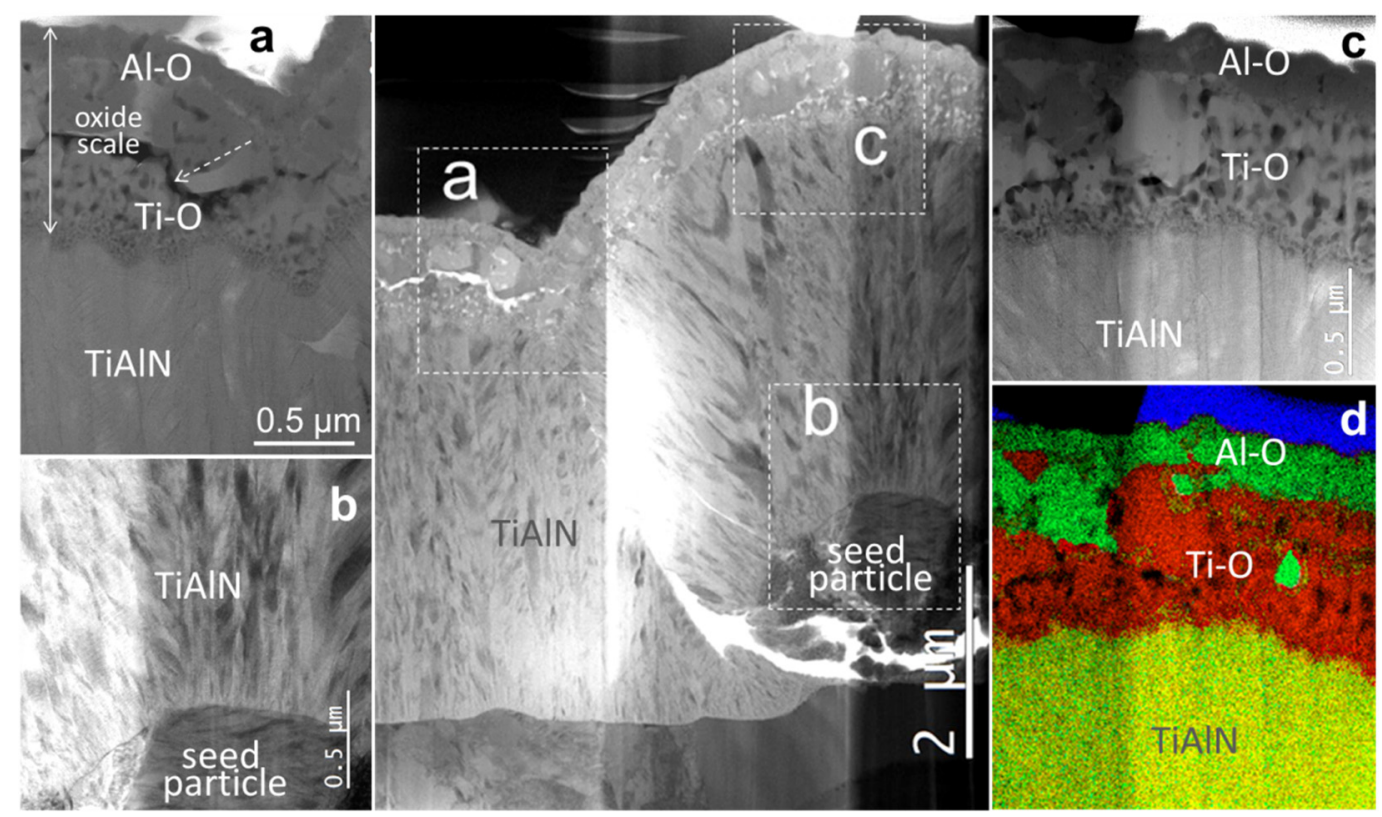

Figure 16. Bright-field STEM cross-sectional image of nodular defect (a-c) and corresponding STEM-EDS map (d) of TiAlN coating oxidized at $850^{\circ} \mathrm{C}$ for $60 \mathrm{~min}$.

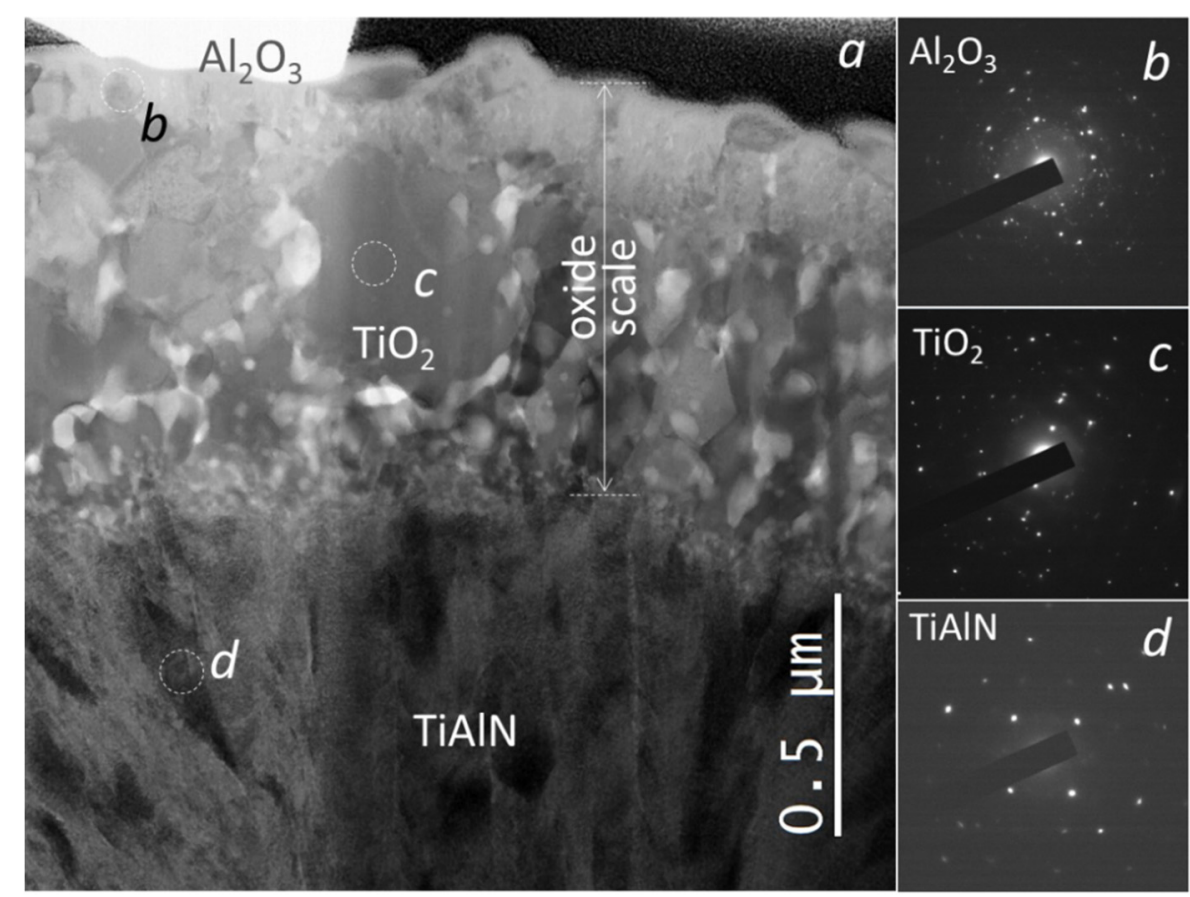

Figure 17. Bright-field STEM cross-sectional image of the oxide scale on TiAlN coating oxidized at $850{ }^{\circ} \mathrm{C}$ for $60 \mathrm{~min}(\mathbf{a})$ and SAED patterns of $\mathrm{Al}_{2} \mathrm{O}_{3}(\mathbf{b}), \mathrm{TiO}_{2}(\mathbf{c})$, and TiAlN (d) crystallites at positions marked with dashed circles.

On the other hand, the outward diffusion of the Ti results in voids or pore formation at the nitride/oxide interface. The STEM images reveal that the Ti-rich oxide zone is composed of a two-layer oxide structure: An outer layer of well-defined crystals (marked by a solid arrow in Figure 15c) and a porous inner layer (adjacent to the rest of the nitride coating, marked by a dashed arrow in Figure 15c). The formation of pores at the nitride/oxide interfaces originates from different diffusion rates of the involved species. In the vicinity of the nodular defect and on its surface, some microcracks parallel to the surface can be 
observed (marked by a dashed arrow in Figure 16a). The formation of such cracks, located in the Ti-rich oxide layer, can be explained by the large compressive stresses that generated at the sites of the topographic irregularities. It can also be observed that during oxidation at $850{ }^{\circ} \mathrm{C}$, the dense columnar microstructure of the as-deposited coating remains unchanged. The substrate/coating interface is also sharp and no changes can be observed.

A further oxidation test at $850{ }^{\circ} \mathrm{C}$ for $120 \mathrm{~min}$ causes the coating to completely oxidize and detach over a large area of the substrate (Figures 8e,f and 18). Only on some small patches is the partial integrity of the oxidized coating still preserved (see inset in Figure $8 \mathrm{e})$. As it can be seen, the oxidized coating is composed of large faceted crystals while its surface is very rough. The titanium and iron diffused on the surface at sites of pores in the Al-rich oxide layer, while outside of this area, the iron diffused deep into the Ti-rich oxide layer. Cracks at the substrate/coating interface are probably due to a large difference in thermal expansion between the coating and substrate. It can be expected that the formation of such cracks accelerates the oxidation process.
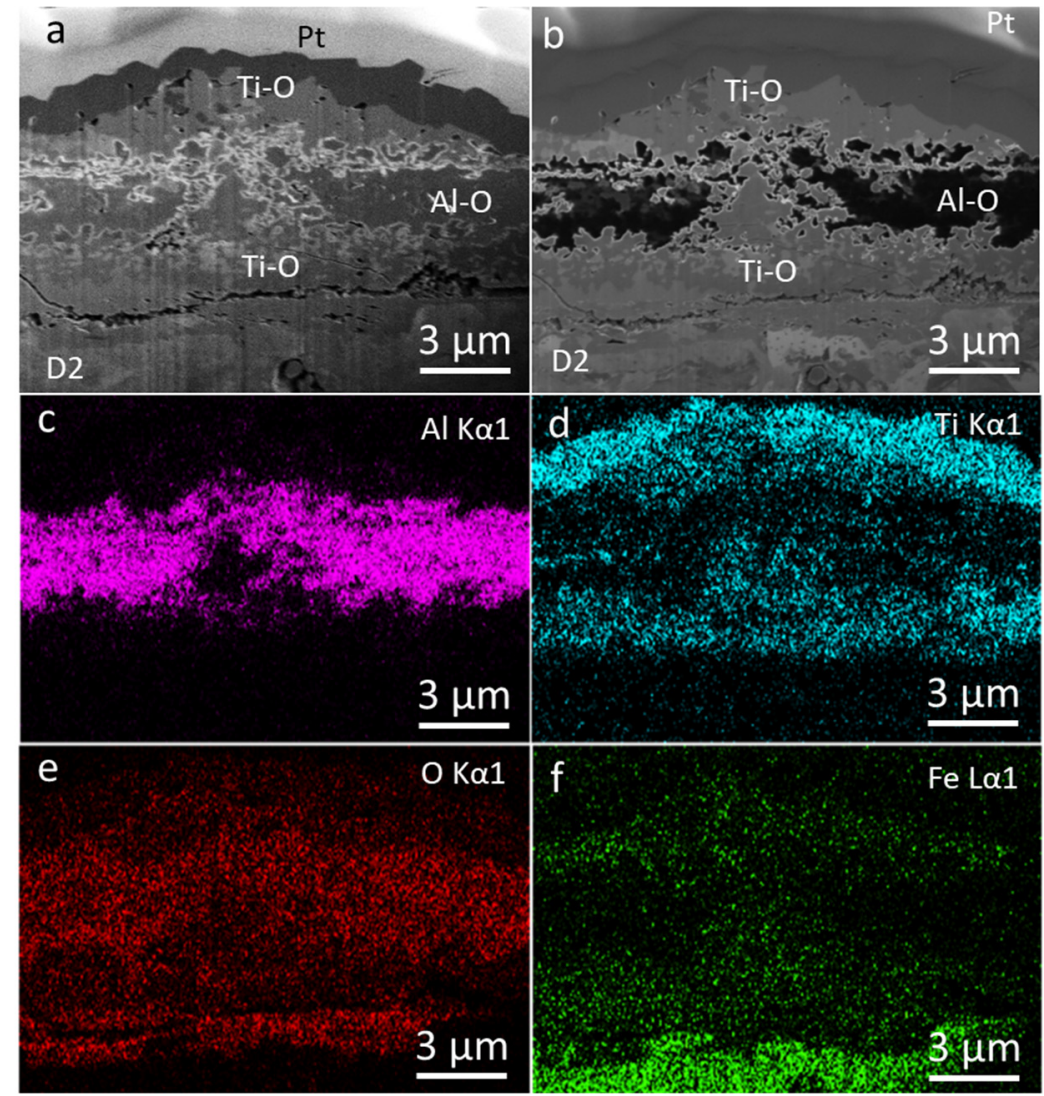

Figure 18. Conventional (a) and ion-generated (b) SEM images of FIB cross-section of sputterdeposited TiAlN hard coating oxidized at $850^{\circ} \mathrm{C}$ for $120 \mathrm{~min}$ and corresponding elemental maps (c-f).

\section{Conclusions}

This study describes the influence of the growth defects on the oxidation process of sputter-deposited TiAlN coatings. The growth of oxide scale at different temperatures $\left(800\right.$ and $850^{\circ} \mathrm{C}$ ) and different periods (15-120 min) was investigated. Simultaneously, the structure of the oxide scale and the interface integrity was also examined. It was found that in the early stage of oxidation, the aluminum oxide layer on the TiAlN grows steadily, maintains integrity, and thus retards the oxidation process. As oxidation continues, pores appear in the alumina layer due to the crystal grain growth in the outer alumina overlayer. The formation of pores is caused by compressive stresses that appear in the underlying Ti-rich oxide layer due to the large difference in molar volume between the oxide and nitride phase. Through such pores, oxygen can rapidly access the oxidation front and 
accelerate the oxidation process. Therefore, this phenomenon strongly affects the global oxidation resistance of the TiAlN coating.

Even more intensive local oxidation takes place at the sites of the growth defects due to the pores that are formed at the rim of the defect. During oxidation, they provide direct paths between the coating surface and the substrate, for transport of oxygen inward and substrate elements to the surface. The intensity of the oxidation process depends on the density of the pores and how open the pathways around the growth defect toward the substrate are. On the other hand, the number and size of pores at the rim of the growth defects depend on the shape and size of seeds or pits on the substrate surface that caused their formation. Thus, the shape of the seed largely determines whether the oxidation down to the substrate will occur or not. It should be noted that not all defects extend through the entire coating. The surface area covered by the growth defects is also relatively small (less than 1\%). Although the early stage always starts at the sites of the growth defects, we believe that their influence on the global oxidation resistance of coatings is not decisive.

Author Contributions: Conceptualization, manuscript writing, P.P.; SEM and FIB analysis of growth defects and oxidized samples, manuscript review, A.D.; STEM analysis, G.D. All authors have read and agreed to the published version of the manuscript.

Funding: This work was funded by the Slovenian Research Agency (program P2-0082). We also acknowledge funding from the European Regional Development Funds (CENN Nanocenter, OP13.1.1.2.02.006).

Institutional Review Board Statement: Not applicable.

Informed Consent Statement: Not applicable.

Data Availability Statement: Data is contained within the article.

Conflicts of Interest: The authors declare no conflict of interest.

\section{References}

1. Jindal, P.C.; Santhanam, A.T.; Schleinkofer, U.; Shuster, A.F. Performance of PVD TiN, TiCN, and TiAlN coated cemented carbide tools in turning. Int. J. Refract. Met. Hard Mater. 1999, 17, 163-170. [CrossRef]

2. Chen, L.; Paulitsch, J.; Du, J.Y.; Mayrhofer, P.M. Thermal stability and oxidation resistance of Ti-Al-N coatings. Surf. Coat. Technol. 2012, 206-318, 2954-2960. [CrossRef]

3. Horling, A.; Hultman, L.; Oden, M.; Sjolen, J.; Karlsson, L. Thermal stability of arc evaporated high aluminium-content TiAlN thin films. J. Vac. Sci. Technol. 2002, 20, 1815-1823. [CrossRef]

4. Mayrhofer, P.H.; Horling, A.; Karlsson, L.; Sjolen, J.; Larsson, T.; Mitterer, C.; Hultman, L. Self-organized nanostructures in the Ti-Al-N system. Appl. Phys. Lett. 2003, 83, 2049. [CrossRef]

5. McIntyre, D.; Greene, J.E.; Håkansson, G.; Sundgren, J.E.; Münz, W.D. Oxidation of metastable single-phase polycristalline $\mathrm{Ti}_{0.5} \mathrm{Al}_{0.5} \mathrm{~N}$ films: Kinetics and mechanisms. J. Appl. Phys. 1990, 67, 1542. [CrossRef]

6. Ichimura, H.; Kawana, A. High-temperature oxidation of ion-plated TiN and TiAlN films. J. Mater. Res. 1993, 8, 1093-1100. [CrossRef]

7. Feng, Z.; Zhang, L.; Ke, R.X.; Wn, Q.L.; Wang, Z.; Lu, Z.H. Thermal stability and oxidation behavior of AlTiN, AlCrN and AlCrSiWN coatings. Int. J. Refract. Met. Hard Mater. 2014, 43, 241-249. [CrossRef]

8. Joshi, A.; Hu, H.S. Oxidation behavior of titanium-aluminium nitrides. Surf. Coat. Technol. 1995, 76-77, 499-507. [CrossRef]

9. Lembke, M.I.; Lewis, D.B.; Münz, W.D. Localised oxidation defects in TiAlN/CrN superlattice structured hard coatings grown by cathodic arc/ unbalanced magnetron deposition on various substrate materials. Surf. Coat. Technol. 2000, 125, 263-268. [CrossRef]

10. Pfeiler, M.; Zechner, J.; Penoy, M.; Michotte, C.; Mitterer, C.; Kathrein, M. Improved oxidation resistance of TiAlN coatings by doping with Si or B. Surf. Coat. Technol. 2009, 203, 3104-3110. [CrossRef]

11. Pfeiler, M.; Scheu, C.; Hutter, H.; Schnöller, J.; Michotte, C.; Mitterer, C.; Kathrein, M. On the effect of Ta on improved oxidation resistance of Ti-Al-Ta-N coatings. J. Vac. Sci. Technol. 2009, 27, 554. [CrossRef]

12. Riedl, H.; Holec, D.; Rachbauer, R.; Polcik, P.; Hollerweger, R.; Paulitsch, J.; Mayrhofer, P.H. Phase stability, mechanical properties and thermal stability of $Y$ alloyed Ti-Al-N coatings. Surf. Coat. Technol. 2013, 235, 174. [CrossRef]

13. Asanuma, H.; Klimashin, F.F.; Polcik, P.; Kolozsvári, S.; Riedl, H.; Mayrhofer, P.H. Impact of lanthanum and boron on the growth, thermomechanical properties and oxidation resistance of Ti-Al-N thin films. Thin Solid Film. 2019, 688, 137239. [CrossRef]

14. Hollerweger, R.; Riedl, H.; Paulitsch, J.; Arndt, M.; Rachbauer, R.; Polcik, P. Origin of high temperature oxidation resistance of Ti-Al-Ta-N coatings. Surf. Coat. Technol. 2014, 257, 78-86. [CrossRef] 
15. Wang, Q.M.; Garkas, W.; Renteria, A.F.; Leyens, C.; Kim, K.H. Oxidation Behaviour of Ti 2 AlN Films Composed Mainly of Nanolaminated MAX Phase. J. Nanosci. Nanotechnol. 2011, 11, 10. [CrossRef] [PubMed]

16. Ikeda, T.; Satoh, H. Phase formation and characterization of hard coatings in the Ti-Al-N system prepared by the cathodic arc ion plating method. Thin Solid Film. 1991, 195, 99-110. [CrossRef]

17. Kim, B.J.; Kim, Z.C.; Nah, J.W.; Lee, J. High temperature oxidation of $\left(\mathrm{Ti}_{1-X} \mathrm{Al}_{\mathrm{X}}\right) \mathrm{N}$ coatings made by plasma enhanced chemical vapor deposition. J. Vac. Sci. Technol. 1999, 17, 133. [CrossRef]

18. Vaz, F.; Rebouta, L.; Andritschky, M.; da Silva, M.F.; Soares, J.C. Oxidation resistance of (Ti,Al,Si)N coatings in air. Surf. Coat. Technol. 1998, 98, 912-917. [CrossRef]

19. Peng, J.; $\mathrm{Su}, \mathrm{D}$.; Wang, C. Combined effect of aluminium content and layer structure on the oxidation performance of $\mathrm{Ti}_{1-\mathrm{x}} \mathrm{Al}_{\mathrm{x}} \mathrm{N}$ based coatings. J. Mater. Sci. Technol. 2014, 30, 803-807. [CrossRef]

20. Hovsepian, P.E.; Ehiasarian, A.P. Six strategies to produce application tailored nanoscale multilayer structured PVD coatings by conventional and High Power Impulse Magnetron Sputtering (HIPIMS). Thin Solid Film 2019, 688, 137409. [CrossRef]

21. Chen, L.; Du, Y.; Xiong, X.; Chang, K.K.; Wu, M.J. Improved properties of Ti-Al-N coating by multilayer structure. Int. J. Refract. Met. Hard Mater. 2011, 29, 681-685. [CrossRef]

22. Hollerweger, R.; Riedl, H.; Arndt, M.; Rachbauer, R.; Kolozsvari, S.; Primig, S.; Mayrhofer, P.H. Guidelines for increasing the oxidation resistance of Ti-Al-N based coatings. Thin Solid Film. 2019, 688, 137290. [CrossRef]

23. Donohue, L.A.; Smith, I.J.; Münz, W.D.; Petrov, I.; Greene, J.E. Microstructure and oxidation-resistance of TiAlCrYN layers grown by combined steered-arc/unbalanced-magnetron-sputter deposition. Surf. Coat. Technol. 1997, 95-96, 226-231. [CrossRef]

24. Vannemann, V.; Stock, H.R.; Kohlscheen, J.; Rambadt, S.; Erkens, G. Oxidation resistance of titanium-aluminium-silicon nitride coatings. Surf. Coat. Technol. 2003, 174-175, 408-415. [CrossRef]

25. Moser, M.; Kiener, D.; Scheu, C.; Mayrhofer, P.H. Influence of Yttrium on the thermal stability of Ti-Al-N thin films. Materials 2010, 3, 1573-1592. [CrossRef]

26. Hovsepian, P.E.; Lewis, D.; Luo, Q.; Münz, W.-D.; Mayrhofer, P.; Mitterer, C.; Zhou, Z.; Rainforth, W. TiAlN based nanoscale multilayer coatings designed to adapt their tribological properties at elevated temperaures. Thin Solid Film. 2005, 485, 160-168. [CrossRef]

27. Wu, G.; Ma, S.; Xu, K.; Chu, P.K. Oxidation resistance of qintuple Ti-Al-Si-C-N coatings and associated mechanism. J. Vac. Sci. Technol. 2012, 30, 041508. [CrossRef]

28. Zhu, L.; Hu, M.; Ni, W.; Liu, Y. High temperature oxidation behavior of TiAlN coating and TiAlSiN coating. Vacuum 2012, 86, 1795-1799. [CrossRef]

29. Polcar, T.; Cavaleiro, A. High temperature behavior of nanolayered CrAlTiN coating: Thermal stability, oxidation and tribological properties. Surf. Coat. Technol. 2014, 257, 70-77. [CrossRef]

30. Xu, Y.X.; Riedl, H.; Holec, D.; Chen, L.; Du, Y.; Mayrhofer, P.H. Thermal stability and oxidation resistance of sputtered TiAlCrN hard coatings. Surf. Coat. Technol. 2017, 324, 48-56. [CrossRef]

31. Sui, X.; Li, G.; Zhou, H.; Zhang, S.; Yu, Y.; Wang, Q.; Hao, J. Evolution behavior of oxide scales of TiAlCrN coatings at high temperature. Surf. Coat. Technol. 2019, 360, 133-139. [CrossRef]

32. Glatz, S.A.; Hollerweger, R.; Polcik, P.; Rachbauer, R.; Paulitsch, J.; Mayrhofer, P.H. Thermal stability and mechanical properties of arc evaporated Ti-Al-Zr-N hard coatings. Surf. Coat. Technol. 2015, 266, 1-9. [CrossRef]

33. Chen, L.; He, L.; Xu, Y.; Zhou, L.; Pei, F.; Du, Y. Influence of ZrN on oxidation resistance of Ti-Al-N coating. Surf. Coat. Technol. 2014, 244, 87-91. [CrossRef]

34. Abadias, G.; Saladukhin, I.A.; Uglov, V.V.; Zlotski, S.V.; Eyidi, D. Thermal stability and oxidation behavior of quaternary TiZrAlN magnetron sputtered thin films: Influence of the pristine microstructure. Surf. Coat. Technol. 2013, 237, 187-195. [CrossRef]

35. Koller, C.M.; Hollerweger, R.; Sabitzer, C.; Rachbauer, R.; Kolozsvári, S.; Paulitsch, J.; Mayrhofer, P.H. Thermal stability and oxidation resistance of arc evaporated TiAlN, TaAlN, TiAlTaN, and TiAlN/TaAlN coatings. Surf. Coat. Technol. 2014, 259, 599-607. [CrossRef]

36. Rachbauer, R.; Holec, D.; Mayrhofer, P.M. Increased thermal stability of Ti-Al-N thin films by Ta alloying. Surf. Coat. Technol. 2012, 211, 98-103. [CrossRef]

37. Khetan, V.; Valle, N.; Duday, D.; Michotte, C.; Ogletree, M.P.D.; Choquet, P. Influence of temperature on oxidation mechanisms of fiber-textured AlTiTaN coatings. Appl. Mat. Interfaces 2014, 6, 4115-4125. [CrossRef]

38. Lembke, M.I. Oxidation Behaviour of TiAlN Based Nanolayered Hard Coatings. Available online: http://shura.shu.ac.uk/19951/ (accessed on 22 January 2021).

39. Fernandes, F.; Morgiel, J.; Polcar, T.; Cavaleiro, A. Oxidation and diffusion processes during annealing of TiSi(V)N films. Surf. Coat. Technol. 2015, 275, 120-126. [CrossRef]

40. Panjan, P.; Drnovšek, A.; Kovač, J.; Gselman, P.; Bončina, T.; Paskvale, S.; Čekada, M.; Kek-Merl, D.; Panjan, M. Oxidation resistance of $\mathrm{CrN} /(\mathrm{Cr}, \mathrm{V}) \mathrm{N}$ hard coatings deposited by DC magnetron sputtering. Thin Solid Film. 2015, 591, 323-329. [CrossRef]

41. Panjan, P.; Drnovšek, A.; Kovač, J.; Čekada, M.; Panjan, M. Oxidation processes in vanadium-based single-layer and nanolayer hard coatings. Vacuum 2017, 138, 230-237. [CrossRef]

42. Panjan, P.; Drnovšek, A.; Gselman, P.; Čekada, M.; Panjan, P.; Boncina, T.; Kek Merl, D. Influence of Growth Defects on the Corrosion Resistance of Sputter-Deposited TiAlN Hard Coatings. Coatings 2019, 9, 511. [CrossRef] 
43. Panjan, P.; Drnovšek, A.; Gselman, P.; Čekada, M.; Panjan, P. Review of Growth Defects in Thin Films Prepared by PVD Techniques. Coatings 2020, 10, 447. [CrossRef]

44. Jehn, H.A. Improvement of the corrosion resistance of PVD hard coating-substrate system. Surf. Coat. Technol. 2000, 125, $212-217$. [CrossRef]

45. Park, H.S.; Kappl, H.; Lee, K.H.; Lee, J.J.; Jehn, H.A.; Fenker, M. Structure modification of magnetron-sputtered CrN coatings by intermediate plasma etching steps. Surf. Coat. Technol. 2000, 133-134, 176-180. [CrossRef]

46. Mattox, D.M. Atomistic Film Growth and Resulting Film Properties. Available online: http://www.htskorea.com/product/ ambios/stress.pdf (accessed on 22 January 2021).

47. Münz, W.D. Titanium aluminum nitride films: A new alternative to TiN coatings. J. Vac. Sci. Technol. A 1986, 4, 2717-2725. [CrossRef] 